\title{
Functional Postnatal Maturation of the Medial Olivocochlear Efferent-Outer Hair Cell Synapse
}

\author{
${ }^{\circledR}$ Lucas G. Vattino, ${ }^{1}{ }^{\circledR}$ Carolina Wedemeyer, ${ }^{1}{ }^{\circledR}$ Ana Belén Elgoyhen, ${ }^{1,2}$ and ${ }^{\circledR}$ Eleonora Katz ${ }^{1,3}$ \\ ${ }^{1}$ Instituto de Investigaciones en Ingeniería Genética y Biología Molecular, Consejo Nacional de Investigaciones Científicas y Técnicas, 1428 Ciudad \\ Autónoma de Buenos Aires, Argentina., ${ }^{2}$ Instituto de Farmacología, Facultad de Medicina, Universidad de Buenos Aires, 1121 Ciudad Autónoma de \\ Buenos Aires, Argentina, and ${ }^{3}$ Departamento de Fisiología, Biología Molecular y Celular, Facultad de Ciencias Exactas y Naturales, Universidad de \\ Buenos Aires, C1428EGA Ciudad Autónoma de Buenos Aires, Argentina
}

The organ of Corti, the auditory mammalian sensory epithelium, contains two types of mechanotransducer cells, inner hair cells (IHCs) and outer hair cells (OHCs). IHCs are involved in conveying acoustic stimuli to the CNS, while OHCs are implicated in the fine tuning and amplification of sounds. OHCs are innervated by medial olivocochlear (MOC) cholinergic efferent fibers. The functional characteristics of the MOC-OHC synapse during maturation were assessed by electrophysiological and pharmacological methods in mouse organs of Corti at postnatal day 11 (P11)-P13, hearing onset in altricial rodents, and at P20-P22 when the OHCs are morphologically and functionally mature. Synaptic currents were recorded in whole-cell voltageclamped OHCs while electrically stimulating the MOC fibers. A progressive increase in the number of functional MOC-OHC synapses, as well as in their strength and efficacy, was observed between P11-13 and P20-22. At hearing onset, the MOCOHC synapse presented facilitation during MOC fibers high-frequency stimulation that disappeared at mature stages. In addition, important changes were found in the VGCC that are coupled to transmitter release. $\mathrm{Ca}^{2+}$ flowing in through L-type VGCCs contribute to trigger ACh release together with P/Q- and R-type VGCCs at P11-P13, but not at P20-P22. Interestingly, N-type VGCCs were found to be involved in this process at P20-P22, but not at hearing onset. Moreover, the degree of compartmentalization of calcium channels with respect to BK channels and presynaptic release components significantly increased from P11-P13 to P20-P22. These results suggest that the MOC-OHC synapse is immature at the onset of hearing.

Key words: BK channels; calcium channels; cochlear efferent synapses; MOC-OHC synapse; short-term synaptic plasticity; synapse maturation

Significance Statement

The functional expression of both VGCCs and BK channels, as well as their localization with respect to the presynaptic components involved in transmitter release, are key elements in determining synaptic efficacy. In this work, we show dynamic changes in the expression of VGCCs and $\mathrm{Ca}^{2+}$-dependent $\mathrm{BK} \mathrm{K}^{+}$channels coupled to $\mathrm{ACh}$ release at the MOC-OHC synapse and their shift in compartmentalization during postnatal maturation. These processes most likely set the short-term plasticity pattern and reliability of the MOC-OHC synapse on high-frequency activity.

\footnotetext{
Received Oct. 8, 2019; revised Apr. 19, 2020; accepted May 11, 2020.

Author contributions: L.G.V., A.B.E. and E.K. designed research; L.G.V. and C.W. performed research; L.G.V. analyzed data; E.K. wrote the paper.

This work was supported by Agencia Nacional de Promoción Científica y Técnica Argentina (A.B.E., E.K.), Universidad de Buenos Aires (E.K.), Scientific Grand Prize of the Fondation Pour I'Audition and National Institutes of Health Grant R01-DC-001508 [Paul Fuchs (Principal Investigator) and A.B.E. (co-Principal Investigator)] to A.B.E. We thank Juan Goutman and Marcelo Moglie for critical discussions and help with data analysis, and Mariano Di Guilmi for critical discussions.

The authors declare no competing financial interests

Correspondence should be addressed to Eleonora Katz at eleokatz@gmail.com.

https://doi.org/10.1523/JNEUROSCI.2409-19.2020

Copyright $\odot 2020$ the authors
}

\section{Introduction}

The organ of Corti, the sensory epithelium of the mammalian inner ear, contains two types of mechanoreceptor cells, inner hair cells (IHCs) and outer hair cells (OHCs), that transform sounds into electrical signals. Upon depolarization by sounds, IHCs release glutamate and activate the auditory nerve fibers contacting them (Hudspeth, 1997; Fuchs et al., 2003), while $\mathrm{OHCs}$ change their length in response to sound-driven voltage variations (Brownell et al., 1985). These shape changes in the OHCs, termed electromotility, are powered by the motor protein prestin and are part of the mechanical feedback process that amplifies low-level sounds (Dallos, 2008). Outer hair cells are innervated by cholinergic efferent fibers of the medial 
olivocochlear (MOC) system (Liberman and Brown, 1986). MOC neurons, activated through several feedback loops from both the periphery and higher processing centers, reduce the sensitivity and sharp tuning of afferent fibers (Ashmore, 2008). We have recently shown that the dynamics of the MOC-OHC synapse directly determine the efficacy of the MOC feedback to the cochlea, being a main player in the gain control of the auditory periphery (Ballestero et al., 2011; Wedemeyer et al., 2018).

In the first 2 postnatal weeks, mouse OHCs undergo several functional and morphologic changes. The most conspicuous are those occurring in $\mathrm{K}^{+}$conductances (Marcotti and Kros, 1999), in the mechanotransduction apparatus, including changes in the stereocilia and associated proteins (Waguespack et al., 2007; Lelli et al., 2009), and in the size and shape of the cell (Marcotti and Kros, 1999; Oliver and Fakler, 1999). Moreover, prestin expression and electromotility, key factors in mature hearing, increase progressively after birth and are not fully functional until postnatal day 14 (P14) to P18 (Oliver and Fakler, 1999; Abe et al., 2007; Hang et al., 2016).

Before hearing onset, at approximately P12 in altricial rodents, MOC fibers transiently innervate the IHCs before reaching their final targets, the OHCs, at the beginning of the second postnatal week (Simmons, 2002). Both MOC-hair cell synapses are mediated by the nicotinic acetylcholine receptor (nAChR) $\alpha 9 \alpha 10$ (Elgoyhen et al., 2001; Weisstaub et al., 2002; Gómez-Casati et al., 2005) functionally coupled to $\mathrm{Ca}^{2+}$-activated $\mathrm{K}^{+}$channels that hyperpolarize the hair cells (Blanchet et al., 1996; Glowatzki and Fuchs, 2000; Oliver et al., 2000; Wersinger et al., 2010). The main function of the efferent system in vertebrate auditory organs is conserved among species; namely, to inhibit hair cells and thereby regulate the dynamic range of hearing (Art et al., 1984; Guinan, 2011). A low resting level of neurotransmitter release and facilitation of responses during high-frequency firing has been described in the turtle papilla (Art and Fettiplace, 1984) and the bullfrog sacculus (Castellano-Muñoz et al., 2010), at the transient efferent synapse to mammalian IHCs (Goutman et al., 2005) and at the MOC-OHC synapse around the onset of hearing (Ballestero et al., 2011; Wedemeyer et al., 2018). Synaptic strength at the mouse transient MOC-IHC synapse increases during postnatal development, and the short-term plasticity (STP) pattern on high-frequency stimulation changes from facilitation at P4 to depression at P9-P11 (Kearney et al., 2019). Moreover, there are changes in the types of voltage-gated $\mathrm{Ca}^{2+}$ channels (VGCCs) coupled to acetylcholine $(\mathrm{ACh})$ release during the short period during which this synapse is functional (Zorrilla de San Martín et al., 2010; Kearney et al., 2019). Taking into account this evidence and that showing that $\mathrm{OHCs}$ undergo significant changes during development, we investigated the synaptic properties, the STP pattern, as well as the localization and types of VGCCs and presynaptic BK channels coupled to ACh release at the mouse MOC-OHC synapse during postnatal maturation. The following two stages were studied: P11$\mathrm{P} 13$, around hearing onset; and P20-P22, when the OHCs are morphologically and functionally mature. Significant changes between these stages were found in the STP pattern and in the types of VGCCs coupled to the release process as well as in their degree of compartmentalization. The present results suggest that the MOC-OHC synapse is still immature at the onset of hearing.

\section{Materials and Methods}

Isolation of the organ of Corti. Procedures for recording from the mouse organ of Corti were identical to those published previously (Ballestero et al., 2011; Wedemeyer et al., 2018). Briefly, apical turns of the organ of
Corti were excised from BALB/c mice of either sex at P11-P13 or P20P22 (considering day of birth as P0), placed in the chamber for electrophysiological recordings mounted on the stage of an upright Leica LFS or Olympus BX51WI microscope and viewed with differential interference contrast using a $40 \times$ water-immersion objective and a camera with contrast enhancement (model C7500-50, Hamamatsu Photonics; or model DMK 23UP1300, The Imaging Source). The preparations were used within $2 \mathrm{~h}$ at $\mathrm{P} 11-\mathrm{P} 13$ and within $1 \mathrm{~h}$ at $\mathrm{P} 20-\mathrm{P} 22$, since the acutely excised organ of Corti from mice at this developmental stage deteriorates faster than those of younger mice. Experimental protocols were performed in accordance with the American Veterinary Medical Association AVMA Guidelines for the Euthanasia of Animals (Leary et al., 2013) and approved by the Institutional Animal Care and Use Committee at Instituto de Investigaciones en Ingeniería Genética y Biología Molecular (Consejo Nacional de Investigaciones Científicas y Técnicas).

Electrophysiological recordings. OHCs were identified by their characteristic shape and three-row arrangement. The cochlear tissue was continuously superfused by means of a peristaltic pump (Gilson Minipuls 3, BioEsanco) with a saline solution of an ionic composition similar to that in the cochlear perilymph, as follows (in $\mathrm{mm}$ ): $155 \mathrm{NaCl}, 5.8 \mathrm{KCl}, 1.3$ $\mathrm{CaCl}_{2}, 0.9 \mathrm{MgCl}_{2}, 0.7 \mathrm{NaH}_{2} \mathrm{PO}_{4}, 5.6$ D-glucose, and 10 HEPES buffer; pH 7.4, 295-305 mOsm. When necessary, drugs and toxins were diluted in this saline and delivered through the perfusion system. Evoked IPSCs (eIPSCs) were obtained in OHCs from the first row in the whole-cell voltage-clamp recording configuration on extracellular electrical stimulation of the MOC fibers. Recordings were made at room temperature $\left(22-25^{\circ} \mathrm{C}\right)$ at a holding potential $\left(V_{\mathrm{h}}\right)$ of $-40 \mathrm{mV}$ using an Axopatch 200B or a Multiclamp 700B amplifier (Molecular Devices). Signals were acquired either with the software pClamp version 9.2 (Molecular Devices) or WinWCP version 5.2.7 (John Dempster, University of Strathclyde, Glasgow, UK; RRID:SCR_014713), low-pass filtered at 2$10 \mathrm{kHz}$ and digitized at $20-50 \mathrm{kHz}$ with a Digidata $1322 \mathrm{~A}$ board (Molecular Devices) or a BNC-2120 board (National Instruments). After breaking into the whole-cell configuration, cell capacitance, resting potential, and voltage-dependent currents were monitored in each $\mathrm{OHC}$ to determine their viability along the experiment. Recordings were obtained with borosilicate glass electrodes (catalog \#1B100F-4, World Precision Instruments) filled with the following (in $\mathrm{mM}$ ): $140 \mathrm{KCl}, 3.5$ $\mathrm{MgCl}_{2}, 0.1 \mathrm{CaCl}_{2}, 5$ EGTA, 5 HEPES buffer, $2.5 \mathrm{Na}_{2} \mathrm{ATP}$; pH 7.2, 283$290 \mathrm{mOsm} ; 6-7.5 \mathrm{M} \Omega$ resistance. Indicated holding potentials were not corrected for liquid junction potentials $(-4 \mathrm{mV})$. Synaptic current analysis was made offline with custom routines implemented in IGOR Pro version 6.37 (WaveMetrics; RRID:SCR_000325).

Electrical stimulation of MOC efferent axons. The cochlear preparation was electrically stimulated to evoke ACh release from presynaptic terminals of the MOC efferent fibers as previously described (Goutman et al., 2005; Ballestero et al., 2011; Wedemeyer et al., 2018). The electrical stimulus was applied through a borosilicate glass pipette of $0.5-1 \mathrm{M} \Omega$ positioned $20 \mu \mathrm{m}$ below the IHC aligned with the OHC under study (Fig. 1A). For optimal stimulation, cochlear supporting cells were gently removed by applying negative pressure through a tip-broken glass pipette. The position of the stimulation electrode was adjusted until eIPSCs in the $\mathrm{OHC}$ were consistently observed. An electrically isolated constant voltage source (Grass model S48 stimulator coupled to a SIU5 isolation unit, A-M Systems) was triggered via the data acquisition software to generate $200-300 \mu \mathrm{A}$ pulses of $0.2-1 \mathrm{~ms}$ duration.

Estimation of the quantum content of transmitter release. Under the assumption that evoked synaptic events in synapses with low release probability follow a Poisson distribution, the quantum content of transmitter release $(m)$ on electrical stimulation of MOC fibers was estimated by the "method of failures," $m=\ln \left(N / N_{0}\right)$ (Del Castillo and Katz, 1954a), where $N$ is the total number of stimuli and $N_{0}$ is the number of failures. Protocols of 100 stimuli at a frequency of $1 \mathrm{~Hz}$ were used to estimate $m$. To test the effect of drugs or toxins on the quantum content of evoked ACh release from the MOC synaptic terminals, $m$ was first assessed two to three times to establish a mean control (Ctrl) value $\left(m_{c}\right)$ before incubating the tissue with the drug or toxin to evaluate. The tissue was then incubated for the time necessary to reach a plateau in the observed effect of the tested compound. Dihydropyridines (DHPs), 
A

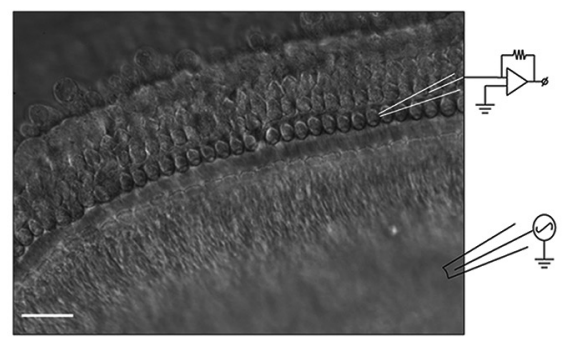

C

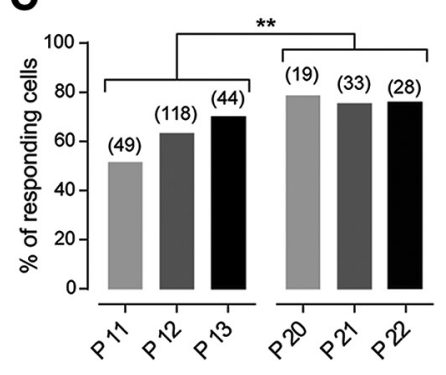

B

D

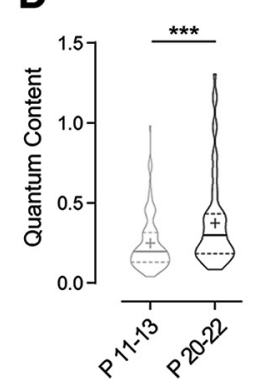

P11-13

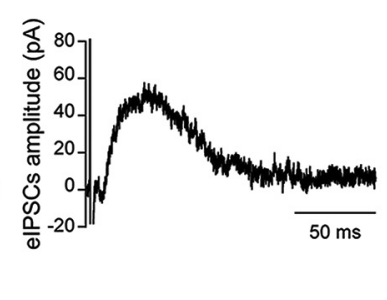

P20-22

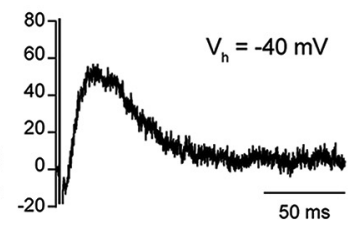

E

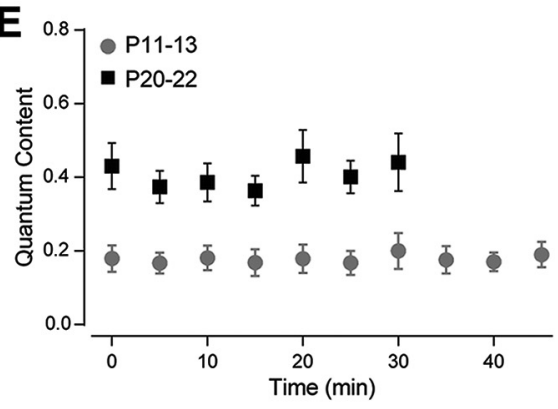

Figure 1. Synaptic strength at the $\mathrm{MOC}-\mathrm{OHC}$ synapse increases with postnatal age. $A$, Schematic representation of the experimental preparation. $\mathrm{OHCs}$ from the first row were recorded with a glass electrode during electrical stimulation of the MOC efferent fibers. Scale bar, $20 \mu \mathrm{m}$. $B$, Representative traces of elPSCs in voltage-clamped OHCs $\left(V_{\mathrm{h}}=-40 \mathrm{mV}\right)$ at P11-P13 (left) and P20-P22 (right) in response to MOC fiber stimulation at $1 \mathrm{~Hz}$. C, Percentage of responding $0 \mathrm{HCS}$ on electrical stimulation of the MOC efferent fibers also increases during postnatal development. Numbers over the bars indicate the number of cells tested. $\chi^{2}$ test; ${ }^{* *} p<0.01$. D, Violin plot for the quantum content of transmitter release at the MOC-OHC synapse (P11-P13, $n=110$ cells; P20-P22, $n=62$ cells). Solid lines represent the median, and dashed lines represent the interquartile divisions. Mean values are represented with the + symbol. MannWhitney test, ${ }^{* * *} p<0.001$. E, Quantum content versus recording time at both developmental stages (P11-P13, $n=6 ; P 20-P 22, n=5$ ). Repeated-measures ANOVA; no significant differences were found within each developmental stage.

iberiotoxin (IbTx) and SNX-482 (SNX) reached a plateau after 5 min of incubation, while $\omega$-agatoxin ( $\omega$-Aga) isovaleric acid (IVA) reached the plateau after $10 \mathrm{~min}$ of incubation and $\omega$-conotoxin GVIA $(\omega$-CgTx), after $15 \mathrm{~min}$. For each compound, three to five measurements after reaching the plateau were used to obtain the mean values of the treatment.

Estimation of the electrical properties and kinetic parameters in the OHCs. OHC membrane resistance $\left(R_{\mathrm{m}}\right)$ and membrane capacitance $\left(C_{\mathrm{m}}\right)$ values were calculated from averages obtained by $5 \mathrm{mV}, 5 \mathrm{~ms}$ depolarizing steps that were applied five times. The protocol used started at $V_{\mathrm{h}}=-70 \mathrm{mV}$, a slightly hyperpolarized potential for OHCs, to guarantee that no voltage-dependent currents are active when measuring the parameters of interest. The amplitude of spontaneous IPSCs (sIPSCs) was calculated as the difference between the holding current value right before the spontaneous event and the peak of the response. To measure eIPSC amplitudes of individual synaptic responses, the difference between the peak and the baseline before the stimulation artifact was computed. Rise and decay kinetics of eIPSCs $\left(\tau_{\text {rise }}, 20-80 \% ; \tau_{\text {decay }}\right.$, $10-90 \%)$ were analyzed only from those synaptic events that were not compromised in shape by the stimulus artifact or by asynchronous release events. The sIPSC and eIPSC halfwidth was calculated as the full width of the synaptic responses at half-maximum amplitude. The sIPSC and eIPSC charge was obtained by integrating the current versus time in each trace.

Paired-pulse and train stimulation protocols. For paired-pulse experiments, MOC efferent fibers were stimulated with a protocol that consisted of 50-100 repetitions (sweeps) of two shocks with interstimulus intervals (ISIs) of $12.5,25,50$, and $100 \mathrm{~ms}$ (stimulation frequencies of 80 , 40,20 , and $10 \mathrm{~Hz}$, respectively). For train stimulation experiments at 10 or $80 \mathrm{~Hz}$, protocols consisted of 30 sweeps for 10-pulse experiments, or a single sweep for 50-pulse voltage-clamp experiments. Current-clamp 50pulse train experiments consisted of three sweeps at $80 \mathrm{~Hz}$. Each protocol was applied at least three times on the same OHC to obtain mean values of the parameters of interest for each cell. For every pulse in paired-pulse and 10-pulse train experiments, the average response (S) was computed as the average of recorded current amplitudes along the number of sweeps, including failures of response, and the probability of release $(\mathrm{P})$ for each pulse was computed as the ratio between the number of eIPSCs and the number of sweeps. The amplitude (A) was obtained by averaging the successful eIPSCs amplitudes after each pulse, computed as the difference between the peak of the response and the baseline, which was considered as the current value before the stimulation artifact. Facilitation indexes (FIs) were then calculated for S, P, and A by normalizing their values in each pulse to those in the first pulse. For 50pulse experiments, the cumulative charge (Q) of the postsynaptic current was obtained by integrating the area under the curve for the evoked postsynaptic response.

Drugs, toxins, and reagents. Reagents were purchased from SigmaAldrich. IbTx was purchased from Tocris Bioscience or Sigma-Aldrich. DHPs nifedipine (Nife) and ( \pm ) Bay-K 8644 (BayK), as well as $\omega$-CgTx, SNX, and $\omega$-Aga, were purchased from Alomone Labs. Invitrogen EGTA-AM was purchased from Thermo Fisher Scientific. All drugs and toxins were thawed and diluted in the extracellular solution just before use. DHPs and EGTA-AM stock solutions were prepared in dimethylsulfoxide (final concentration during the experiment, $\leq 0.1 \%$ ). Peptidic toxin stock solutions were prepared in distilled water and coapplied through the perfusion system with bovine serum albumin (final concentration during the experiment, $\leq 0.01 \%$ ).

Statistics. All statistical tests were performed using custom routines implemented in $\mathrm{R}$ version 3.6.3 ( $\mathrm{R}$ Development Core Team) through RStudio software version 1.0.153 (RRID:SCR_000432), except for the $\chi^{2}$ test, performed using GraphPad Prism 6 (RRID:SCR_002798). Before performing any analysis, data were tested for normal distribution using the Shapiro-Wilk normality test, and parametric or nonparametric tests were applied accordingly. For statistical analyses with two datasets, twotailed paired and unpaired $t$ tests or two-sided Wilcoxon rank sum and Mann-Whitney tests were used. For comparisons of more than two datasets, one-way ANOVA or repeated-measures ANOVA followed by Tukey's multiple-comparison test were used when data were normally distributed. If a dataset was not normally distributed, Kruskal-Wallis or 
Friedman tests followed by Dunn or Conover multiple-comparison tests, respectively, were used. When more than two datasets were compared and significant differences were found, the reported $p$ values correspond to the post hoc multiple-comparison test. Values of $p<0.05$ were considered significant. When significant differences were found, effect sizes were calculated using the rstatix statistical package in R. Effect size coefficients used were Hedges' $\mathrm{g}$ for paired and unpaired $t$ tests, Wilcoxon's $r$ for Wilcoxon and Mann-Whitney tests, partial $\eta^{2}\left(\eta_{\mathrm{p}}^{2}\right)$ for ANOVA and repeated-measures ANOVA, and Kendall's W for Friedman tests. All data are expressed as the mean \pm SEM. In all cases, $n$ indicates the number of cells tested, and for each of the reported experiments, at least three animals were used. The statistical test used in each case is reported in the figure legend.

\section{Results}

\section{Synaptic strength at the MOC-OHC synapse increases during postnatal development}

Outer hair cells start to be innervated by MOC efferent fibers at the second postnatal week (Dulon et al., 1998; He and Dallos, 1999; Simmons, 2002; Roux et al., 2011). In previous work, we showed that the quantum content of $\mathrm{ACh}$ release at the MOCOHC synapse around the onset of hearing (P11-P13) is very low at $1 \mathrm{~Hz}$ stimulation. However, postsynaptic responses are significantly enhanced on increasing the stimulus frequency due to both presynaptic facilitation and postsynaptic summation (Ballestero et al., 2011; Wedemeyer et al., 2018). In the present work, we studied whether the strength of synaptic transmission changes during postnatal development. To this end, we evaluated both the number of OHCs presenting postsynaptic currents on electrical stimulation of the MOC fibers and the quantum content of evoked release of each responding cell, both at the onset of hearing (P11-P13) and at a more mature stage (P20-P22). Near the physiological OHC membrane resting potential, which is approximately $-50 \mathrm{mV}$ (Dallos, 1985), synaptic currents are outward (Fig. 1B), therefore inhibitory. Inhibition arises because the MOC-OHC synapse is mediated by the activation of the $\alpha 9 \alpha 10 \mathrm{nAChR}$ coupled to the activation of $\mathrm{Ca}^{2+}$-activated $\mathrm{K}^{+}$ channels that hyperpolarize the hair cells (Oliver et al., 2000; Elgoyhen et al., 2001; Wersinger et al., 2010; Ballestero et al., 2011; Rohmann et al., 2015). Under our recording conditions, the resting membrane potential on break-in was approximately $-60 \mathrm{mV}$, and there were no significant differences in this parameter between P11-P13 and P20-P22 (Table 1: P11-P13, $n=54$ cells; P20-P22, $n=31$ cells; $p=0.6252$ ).

The number of functionally innervated OHCs significantly increased during maturation. At P11-P13, only 131 of 211 cells tested responded to electrical stimulation of the MOC fibers, whereas at P20-P22, 62 of 80 cells tested responded ( $\chi^{2}$ test: $\chi^{2}=6.171, \mathrm{df}=1, z=2.484, p=0.0065$; Fig. $\left.1 C\right)$. In addition, the $m$ values of responding cells significantly increased during maturation (P11-P13: $m=0.24 \pm 0.02, n=110$ cells; P20-P22: $0.37 \pm 0.03, n=62$ cells; $p=0.0004$, Wilcoxon's $r=0.27$; Fig. $1 D$ ). It is important to note, as illustrated by the violin plot in Figure $1 D$, that there is variability in this parameter and that in some cases $m$ values obtained at P11-P13 overlap with those at P20P22. We also tested the stability of this parameter at both age groups. At P11-P13, $m$ remains stable for at least $45 \mathrm{~min}$, whereas at P20-P22, due to the faster deterioration of the cochlear tissue at this stage (see Materials and Methods), we only tested its stability for $30 \mathrm{~min}$ (P11-P13: $n=6$ cells, $p=0.9391$; P20-P22: $n=5$ cells, $p=0.2835$; Fig. $1 E$ ).

During development, there was a significant increase in $\mathrm{OHC}$ membrane capacitance and a significant reduction in membrane
Table 1. Membrane properties of $\mathrm{OHCs}$ during postnatal development

\begin{tabular}{lcc}
\hline & $\mathrm{P} 11-\mathrm{P} 13(n=54)$ & $\mathrm{P} 20-\mathrm{P} 22(n=31)$ \\
\hline$V_{\mathrm{m}}(\mathrm{mV})$ & $-63.43 \pm 1.02$ & $-62.98 \pm 0.88$ \\
$C_{\mathrm{m}}(\mathrm{pF})$ & $11.54 \pm 0.22$ & $15.87 \pm 0.43^{* * *}$ \\
$R_{\mathrm{m}}(\mathrm{M} \Omega)$ & $123.56 \pm 3.18$ & $40.50 \pm 2.43^{* * *}$ \\
\hline
\end{tabular}

Unpaired $t$ test, ${ }^{* * *} p<0.001$.

Table 2. Properties of IPSCs in OHCs from mice during postnatal development

\begin{tabular}{llrr}
\hline & & \multicolumn{1}{c}{ P11-P13 } & \multicolumn{1}{c}{ P20-P22 } \\
\hline sIPSCs & Amplitude (pA) & $33.98 \pm 3.07$ & $31.97 \pm 3.52$ \\
$(\mathrm{P} 11-\mathrm{P} 13, n=6)$ & $\tau_{\text {rise }}(\mathrm{ms})(20-80 \%)$ & $18.78 \pm 1.85$ & $16.13 \pm 2.44$ \\
$(\mathrm{P} 20-\mathrm{P} 22, n=5)$ & $\tau_{\text {decay }}(\mathrm{ms})(10-90 \%)$ & $47.70 \pm 9.30$ & $32.31 \pm 4.03$ \\
& Halfwidth (ms) & $32.93 \pm 5.58$ & $30.08 \pm 3.78$ \\
& Q (pC) & $2.49 \pm 0.42$ & $2.10 \pm 0.23$ \\
elPSCs & Amplitude (pA) & $30.20 \pm 1.53$ & $34.93 \pm 2.08$ \\
(P11-P13, $n=32)$ & $\tau_{\text {rise }}(\mathrm{ms})(20-80 \%)$ & $11.37 \pm 0.88$ & $12.14 \pm 0.87$ \\
(P20-P22, $n=17)$ & $\tau_{\text {decay }}(\mathrm{ms})(10-90 \%)$ & $44.47 \pm 2.31$ & $42.38 \pm 2.14$ \\
& Halfwidth (ms) & $44.39 \pm 1.78$ & $41.68 \pm 1.63$ \\
& $Q$ (pC) & $1.83 \pm 0.11$ & $1.92 \pm 0.13$ \\
\hline
\end{tabular}

resistance $\left(p=2 \times 10^{-5}\right.$, Wilcoxon's $r=0.62$; and $p=2.7 \times 10^{-7}$, Wilcoxon's $r=0.83$, respectively; Table 1; P11-P13, $n=54$ cells; $\mathrm{P} 20-\mathrm{P} 22, n=31$ cells). This agrees with the increment in OHC size and also with the increment in $\mathrm{K}^{+}$currents during this period (Marcotti and Kros, 1999; Oliver and Fakler, 1999). These changes in OHC membrane properties did not alter the response of the cell to the spontaneous release of ACh by the MOC fibers. The amplitude of sIPSCs did not change between P11-P13 and P20P22 $(p=0.6143$; Table 2), indicating that the quantum size remained constant during this period. In addition, no significant changes were observed between both age groups in SIPSCs kinetics $\left(\tau_{\text {rise }}, p=0.1775 ; \tau_{\text {decay }}, p=0.2102 ; n=5-6\right.$ cells; Table 2$)$, which have been shown to be dominated by the $\mathrm{Ca}^{2+}$ gating of the SK2 channel (Oliver et al., 2000). This suggests that the functional coupling of the SK2 channel to the nAChR did not change during this developmental period. Moreover, in agreement with these results, we found that the total charge going through the postsynaptic membrane on each synaptic event did not change during the studied period ( $p=0.4471, n=5-6$ cells; Table 2 ).

We also analyzed the characteristics of eIPSCs in both age groups, summarized in Table 2 (P11-P13, $n=32$ cells; P20-P22, $n=17$ cells) and found that there were no significant differences either in the kinetic parameters $\left(\tau_{\text {rise }}, p=0.9495, \tau_{\text {decay }}\right.$, $p=0.5002)$, in the amplitude $(p=0.4779)$, or in the total charge going through the postsynaptic membrane on each synaptic event during the studied period $(\mathrm{Q}, p=0.6371)$. The lack of changes in the amplitude of successful events suggests that synaptic strength increases with maturation due to an increment in the probability of successfully evoking a release event, without increments in the average number of vesicles released per action potential. In addition, the fact that no changes were observed in eIPSCs kinetics on maturation indicate that as previously shown at P11-P13, the summation of postsynaptic responses due to the slow decay kinetics of eIPSCs would be an important factor contributing to enhanced inhibition of OHC activity when MOC fibers fire at high frequency (Ballestero et al., 2011; Wedemeyer et al., 2018).

Paired-pulse facilitation at the MOC-OHC synapse is absent in hearing mice (P20-P22)

The significant increment in quantum content observed at the MOC-OHC synapse between hearing onset (P11-P13) and a 
A

\section{P11-13}

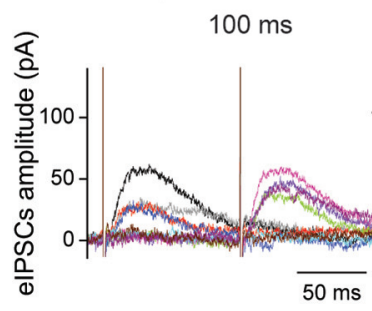

P20-22

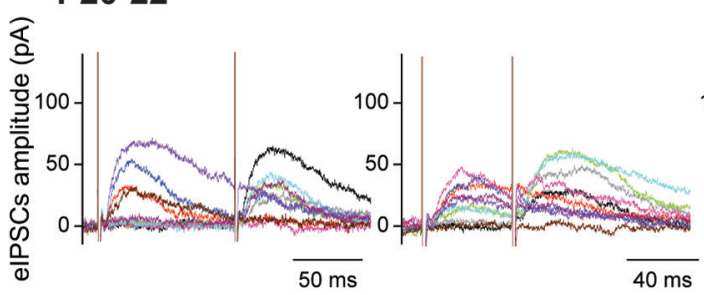

$50 \mathrm{~ms}$

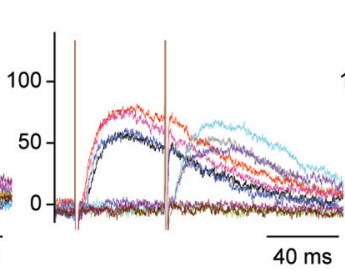

$25 \mathrm{~ms}$

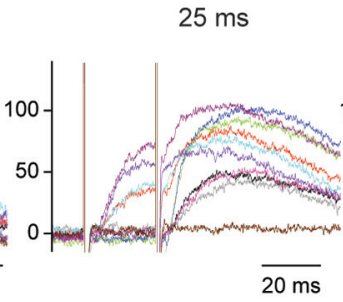

B

\section{P11-13}

Figure 2. Paired-pulse facilitation observed at the $\mathrm{MOC}-\mathrm{OHC}$ synapse around the onset of hearing is absent in hearing mice. $\boldsymbol{A}$, Representative traces of 10 individual responses during paired-pulse stimulation protocols at P11-P13 (top) and P20-P22 (bottom). ISls are 12.5, 25, 50, and $100 \mathrm{~ms}$, corresponding to M0C stimulation frequencies of 80 , 40, 20, and 10 Hz, respectively. Individual traces are represented with different colors for clarification purposes. $\boldsymbol{B}$, Facilitation indexes $\left(\mathrm{FI}=\mathrm{X}_{2} / \mathrm{X}_{1}\right)$ for the total average response, $\mathrm{Fl}_{\mathrm{S}}$, the release probability, $\mathrm{F} \mathrm{P}_{\mathrm{P}}$, and the amplitude of successfully evoked postsynaptic responses, $\mathrm{Fl}_{\mathrm{A}}$ plotted as a function of the ISls tested. At the onset of hearing (P11-P13, top) at ISIs of 12.5 and 25 ms, $\mathrm{Fl}_{S}$ and $\mathrm{Fl}$ Pere $>1$, whereas $\mathrm{FI}_{\mathrm{A}}$ is close to 1 for all ISls tested $(n=6-7)$. Paired $t$ test or Wilcoxon rank sum test: ${ }^{*} p<0.05$ and ${ }^{* *} p<0.01$ for $\mathrm{FI}_{S}$ and $\mathrm{Fl}_{\mathrm{P}}$. At $\mathrm{P} 20-\mathrm{P} 22$ (bottom), $\mathrm{FI}_{S}, \mathrm{Fl}_{\mathrm{P}}$, and $\mathrm{FI}_{\mathrm{A}}$ were not significantly different from 1 within all ISIs tested $(n=5-6)$. See Table 3 for details.

Table 3. Calculation of $\mathrm{FI}_{\mathrm{X}}=\mathrm{X}_{2} / \mathrm{X}_{1}$ for $\mathrm{S}, \mathrm{P}$, and $\mathrm{A}$ at the $\mathrm{MOC}-\mathrm{OHC}$ synapse, during postnatal development

\begin{tabular}{|c|c|c|c|c|c|c|}
\hline \multirow[b]{2}{*}{ ISIs } & \multicolumn{3}{|c|}{ P11-P13 $(n=6-7)$} & \multicolumn{3}{|c|}{$\mathrm{P} 20-\mathrm{P} 22(n=5-6)$} \\
\hline & $\mathrm{Fl}_{\mathrm{S}}=\mathrm{S}_{2} / \mathrm{S}_{1}$ & $\mathrm{Fl}_{\mathrm{p}}=\mathrm{P}_{2} / \mathrm{P}_{1}$ & $\mathrm{Fl}_{\mathrm{A}}=\mathrm{A}_{2} / \mathrm{A}_{1}$ & $\mathrm{Fl}_{\mathrm{S}}=\mathrm{S}_{2} / \mathrm{S}_{1}$ & $\mathrm{Fl}_{\mathrm{p}}=\mathrm{P}_{2} / \mathrm{P}_{1}$ & $\mathrm{Fl}_{\mathrm{A}}=\mathrm{A}_{2} / \mathrm{A}_{1}$ \\
\hline $100 \mathrm{~ms}(10 \mathrm{~Hz})$ & $1.13 \pm 0.16$ & $0.97 \pm 0.09$ & $1.11 \pm 0.06$ & $0.83 \pm 0.11$ & $0.92 \pm 0.10$ & $0.89 \pm 0.04$ \\
\hline $50 \mathrm{~ms}(20 \mathrm{~Hz})$ & $0.98 \pm 0.15$ & $1.06 \pm 0.16$ & $0.92 \pm 0.02$ & $0.72 \pm 0.08$ & $0.85 \pm 0.08$ & $0.84 \pm 0.04$ \\
\hline $25 \mathrm{~ms}(40 \mathrm{~Hz})$ & $1.80 \pm 0.20^{*}$ & $1.58 \pm 0.13^{*}$ & $1.12 \pm 0.05$ & $0.84 \pm 0.17$ & $0.76 \pm 0.08$ & $0.96 \pm 0.13$ \\
\hline $12.5 \mathrm{~ms}(80 \mathrm{~Hz})$ & $2.66 \pm 0.24^{* *}$ & $2.54 \pm 0.19^{* *}$ & $1.07 \pm 0.04$ & $1.20 \pm 0.18$ & $1.08 \pm 0.13$ & $1.11 \pm 0.11$ \\
\hline
\end{tabular}

Paired $t$ test or Wilcoxon rank sum test, ${ }^{*} p<0.05 ;{ }^{* *} p<0.01$.

more mature stage (P20-P22) led us to investigate whether this increment was reflected in the behavior of this synapse on highfrequency stimulation of the MOC fibers. Synapses that present low quantum content tend to facilitate on high-frequency stimulation (Debanne et al., 1996; Murthy et al., 1997; Zucker and Regehr, 2002), as was observed at the mouse MOC-OHC synapse at the onset of hearing (Ballestero et al., 2011), at neonatal rat and mouse MOC-IHC synapses (Goutman et al., 2005; Kearney et al., 2019), and also at efferent synapses on turtle and frog hair cells (Art et al., 1984; Castellano-Muñoz et al., 2010). To evaluate whether there were changes in the paired-pulse FI between the two age groups under study, the S, P and the average A values on MOC stimulation were measured for paired pulses with ISIs ranging from 12.5 to $100 \mathrm{~ms}$, corresponding to MOC stimulation frequencies between 80 and $10 \mathrm{~Hz}$, respectively (Fig. $2 A)$. The FI was defined as the ratio $X_{2} / X_{1}$, where $X_{1}$ and $X_{2}$ are the values for $\mathrm{S}, \mathrm{P}$, or $\mathrm{A}$ obtained in the $\mathrm{OHCs}$ in response to the first and the second pulse, respectively (Fig. $2 B$ ). FI values $>1$ indicate facilitation, while FI values $<1$ indicate depression (Del Castillo and Katz, 1954b; Mallart and Martin, 1967; Katz and Miledi, 1968; Goutman et al., 2005; Ballestero et al., 2011; Kearney et al., 2019). At the onset of hearing (P11-P13; Fig. 2A, $B$, top) $\mathrm{S}_{2} / \mathrm{S}_{1}$ and $\mathrm{P}_{2} / \mathrm{P}_{1}$ ratios were significantly $>1$ for ISIs of 12.5 and $25 \mathrm{~ms}$ ( 80 and $40 \mathrm{~Hz}$, respectively), whereas the $\mathrm{A}_{2} / \mathrm{A}_{1}$ ratio was close to 1 for all ISIs tested $\left(100 \mathrm{~ms}\right.$ : $\mathrm{FI}_{\mathrm{S}}, p=0.99 ; \mathrm{FI}_{\mathrm{P}}$, $p=0.8119 ; \mathrm{FI}_{\mathrm{A}}, p=0.6369 ; 50 \mathrm{~ms}: \mathrm{FI}_{\mathrm{S}}, p=0.99 ; \mathrm{FI}_{\mathrm{P}}, p=0.9309$;
$\mathrm{FI}_{\mathrm{A}}, p=0.9183 ; 25$ ms: $\mathrm{FI}_{\mathrm{S}}, p=0.03125$; Wilcoxon's $r=0.58 ; \mathrm{FI}_{\mathrm{P}}$, $p=0.0013 ;$ Hedge's $\mathrm{g}=1.45 ; \mathrm{FI}_{\mathrm{A}}, p=0.5781 ; 12.5 \mathrm{~ms}: \mathrm{FI}_{\mathrm{S}}$, $p=0.0065$, Hedge's $\mathrm{g}=1.71 ; \mathrm{FI}_{\mathrm{P}}, p=0.0085$, Hedge's $\mathrm{g}=1.55$; $\mathrm{FI}_{\mathrm{A}}, p=0.2006 ; n=6-7$ cells; Table 3 ). These results indicate that facilitation of the $\mathrm{S}$ values at P11-P13 can be accounted for entirely by an increase in the $\mathrm{P}$ values. Therefore, as previously reported (Ballestero et al., 2011) at the MOC-OHC synapse, facilitation in response to high-frequency stimulation is of presynaptic origin. At P20-P22 (Fig. 2A,B, bottom), however, FI values for $\mathrm{S}, \mathrm{P}$, and A were not significantly different from 1 at any of the ISIs tested $\left(100 \mathrm{~ms}: \mathrm{FI}_{\mathrm{S}}, p=0.3125 ; \mathrm{FI}_{\mathrm{P}}, p=0.558 ; \mathrm{FI}_{\mathrm{A}}\right.$, $p=0.0625 ; 50 \mathrm{~ms}: \mathrm{FI}_{\mathrm{S}}, p=0.0625 ; \mathrm{FI}_{\mathrm{P}}, p=0.2155 ; \mathrm{FI}_{\mathrm{A}}, p=0.125$; $25 \mathrm{~ms}: \mathrm{FI}_{\mathrm{S}}, p=0.3125 ; \mathrm{FI}_{\mathrm{P}}, p=0.1789 ; \mathrm{FI}_{\mathrm{A}}, p=0.4375 ; 12.5 \mathrm{~ms}$ : $\mathrm{FI}_{\mathrm{S}}, p=0.7261 ; \mathrm{FI}_{\mathrm{P}}, p=0.4908 ; \mathrm{FI}_{\mathrm{A}}, p=0.3125 ; n=6$ cells; Table $3)$. The present results show that the facilitation of responses on high-frequency stimulation is lost as the MOC-OHC synapse matures and transmitter release becomes more reliable on lowfrequency firing of the MOC fibers.

\section{Developmental changes in the contribution of presynaptic VGCCs to $\mathrm{ACh}$ release at the MOC-OHC synapse}

In mammals, fast synaptic transmission at both central and peripheral synapses is mediated by multiple types of VGCCs, including $\mathrm{P} / \mathrm{Q}, \mathrm{N}$, and $\mathrm{R}\left(\mathrm{Ca}_{\mathrm{v}} 2.1, \mathrm{Ca}_{\mathrm{v}} 2.2\right.$, and $\mathrm{Ca}_{\mathrm{v}} 2.3$, respectively; Katz et al., 1997; Plant et al., 1998; Reid et al., 2003; Catterall and Few, 2008; Catterall, 2011). $\mathrm{Ca}^{2+}$ channels coupled 
A
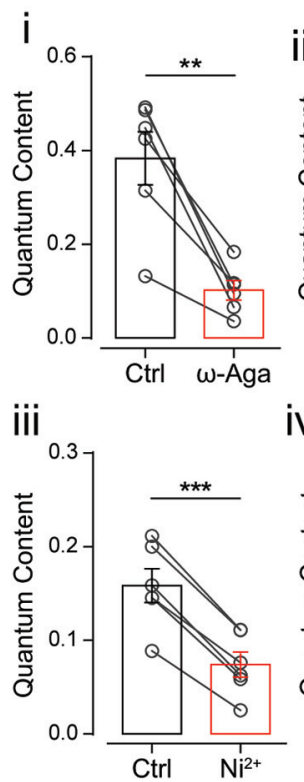

C

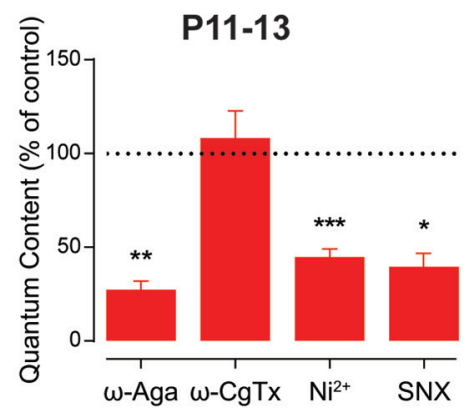

E

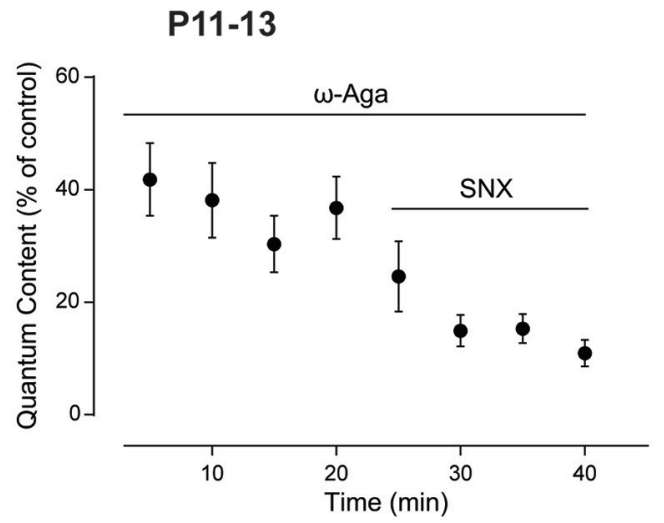

P20-22

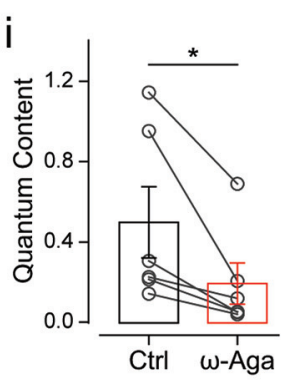

iii

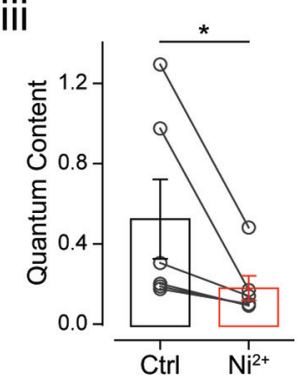

D

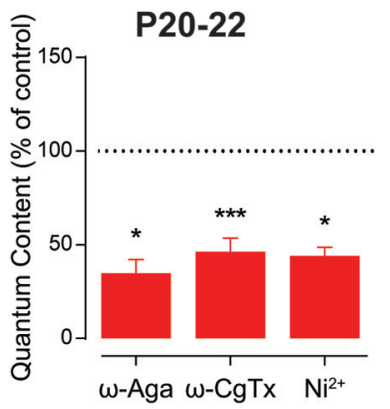

$\mathbf{F}$

P11-13

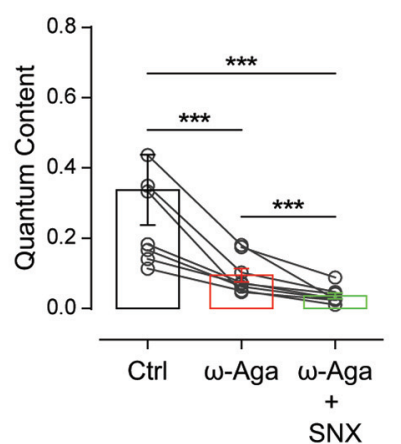

Figure 3. Differential contribution of VGCCs supporting $A C h$ release at the $M O C-O H C$ synapse at two different postnatal developmental stages. $\boldsymbol{A}, \boldsymbol{B}$, Effect of $200 \mathrm{~nm} \omega$-Aga, $500 \mathrm{~nm} \omega$-CgTx, $100 \mu \mathrm{m} \mathrm{Ni}{ }^{2+}$, and $500 \mathrm{~nm} \mathrm{SNX,} \mathrm{specific} \mathrm{blockers} \mathrm{of} \mathrm{P/Q-,}$ $\mathrm{N}$-, and R-type VGCCS, respectively, on the quantum content of evoked release at P11-P13 $(\boldsymbol{A})$ and P20-P22 (B). C, D, Summary of the data in $\boldsymbol{A}$ and $\boldsymbol{B}$, expressed as a percentage of control quantum content. $\boldsymbol{E}, \boldsymbol{F}$, Time dependence $(\boldsymbol{E})$ and total effect $(\boldsymbol{F})$ of the sequential application to the bath solution of $200 \mathrm{~nm} \omega$-Aga and $500 \mathrm{~nm}$ SNX, specific blockers of P/Q- and Rtype VGCCs, respectively, at P11-P13. Values for $\omega$-Aga and SNX shown in $\boldsymbol{F}$ correspond to the last two points of each treatment in $\boldsymbol{E}$. Paired $t$ test or Wilcoxon rank sum test for $\boldsymbol{A}-\boldsymbol{D}$; Friedman test followed by Conover post hoc comparisons for $\boldsymbol{F}$; ${ }^{*} p<0.05,{ }^{* *} p<0.01,{ }^{* * *} p<0.001$.

to transmitter release have been shown to be developmentally regulated both at central synapses (Iwasaki et al., 2000; Momiyama, 2003; Fedchyshyn and Wang, 2005) and at the neuromuscular junction (Rosato Siri and Uchitel, 1999). In previous work, we showed, by electrophysiological and pharmacological methods, that the VGCCs coupled to transmitter release at the transient MOCIHC synapse are also developmentally regulated (Kearney et al., 2019). From P4 to $\mathrm{P} 7, \mathrm{ACh}$ release is mediated by $\mathrm{P} / \mathrm{Q}-$, $\mathrm{R}-$, and, under certain circumstances, also by L-type VGCCs, whereas at $\mathrm{P} 9-\mathrm{P} 11$, transmitter release is mediated only by P/Q- and N-type VGCCs (Zorrilla de San Martín et al., 2010; Kearney et al., 2019).

In view of these developmental changes reported at the MOC-IHC synapse, we investigated which types of VGCCs are coupled to ACh release at the MOC-OHC synapse both at P11-P13 and at P20-P22. To this end, we evaluated the quantum content of transmitter release in the presence of toxins that specifically antagonize P/Q-, N-, and R-type VGCCs. $\omega$-Aga (200 nM) and $\omega$-CgTx (500 nM) were used to block P/Q- and Ntype VGCCs, respectively. SNX (500 nM) and $\mathrm{Ni}^{2+}(100 \mu \mathrm{M})$ were used to block Rtype VGCCs (Mintz and Bean, 1993; Olivera et al., 1994; Newcomb et al., 1998; Bourinet et al., 2001). At the onset of hearing, $m$ was significantly reduced by $\omega$-Aga-IVA, SNX, and $\mathrm{Ni}^{2+}$, but was not affected by $\omega$-CgTx (Fig. $3 A ; m_{\mathrm{c}}=$ $0.383 \pm 0.057, m_{\text {Aga }}=0.102 \pm 0.021, p=$ 0.00243 , Hedge's $g=2.49 ; m_{c}=0.371 \pm$ $0.084, m_{\mathrm{SNX}}=0.162 \pm 0.048, p=0.0072$, Hedge's $g=1.07 ; \quad m_{\mathrm{c}}=0.158 \pm 0.018$, $m_{\mathrm{Ni}}=0.007 \pm 0.014, \quad p=3 \times 10^{-5}$, Hedge's $g=1.99 ; \quad m_{\mathrm{c}}=0.227 \pm 0.073$, $m_{\text {CgTx }}=0.254 \pm 0.089, p=0.5781 ; n=6-7$ cells). SNX is a more selective blocker of R-type VGCCs than $\mathrm{Ni}^{2+}$, as this latter compound also blocks T-type VGCCs (Lee et al., 1999; Chow et al., 2003; Obejero-Paz et al., 2008). Notwithstanding, T-type channels have only been detected in the hair cells (Inagaki et al., 2008; Levic and Dulon, 2012) and not in lateral olivocochlear fibers (Gáborján and Vizi, 1999) or MOC fibers (Waka et al., 2003). In addition, we found no significant differences in the effect of SNX and $\mathrm{Ni}^{2+}$ on $m$ (unpaired $t$ test, $p=0.1239$ ), which is consistent with the similar block that these VGCC antagonists exert on synaptic transmission at cerebellar synapses (Myoga and Regehr, 2011). Therefore, we only used $\mathrm{Ni}^{2+}$ to evaluate whether $\mathrm{R}$ type VGCCs were coupled to ACh release at P20-P22. At this age group, the three VGCC blockers tested exerted a significant effect on $m$ (Fig. $3 B ; m_{c}=0.501 \pm$ $0.177, m_{\text {Aga }}=0.197 \pm 0.103 ; p=0.0312$, Wilcoxon's $r=0.62 ; m_{\mathrm{c}}=$ $0.534 \pm 0.199, m_{\mathrm{Ni}}=0.191 \pm 0.062, p=0.0312$, Wilcoxon's $r=0.62$; $m_{\mathrm{c}}=0.199 \pm 0.017, m_{\mathrm{CgTx}}=0.096 \pm 0.021, p=0.0003$, Hedge's 
$\mathrm{g}=2.07 ; n=6$ cells). The fact that at both age groups the summed effect of the VGCC antagonists applied separately blocked $>100 \%$ of $m(\sim 130 \%$ at P11-P13 and $\sim 170 \%$ at P20-P22) can be in part accounted for by the fact that the relationship between external $\mathrm{Ca}^{2+}$ and the amount of transmitter released by the synaptic terminal, as first described at the neuromuscular junction (Dodge and Rahamimoff, 1967) and later at several central mammalian and peripheral synapses (Mintz et al., 1995; Borst and Sakmann, 1996; Takahashi et al., 1996; Wu et al., 1999; Rosato-Siri et al., 2002), including the transient mouse MOC-IHC synapse (Zorrilla de San Martín et al., 2010), is highly nonlinear. Therefore, small variations in the amount of $\mathrm{Ca}^{2+}$ in the external milieu or in the activity of terminal membrane VGCCs might exert a great impact on transmitter release.

The sequential application of $\omega$-Aga-IVA and SNX at P11P13, however, shows there is still a small fraction $(\sim 10 \%)$ of $m$ that remains unblocked even in the presence of both VGCC antagonists. Figure $3 E$ illustrates the temporal course of the effects of each toxin (percentage of control: $m_{\text {Aga }}=36.77 \pm 5.53 \%$; $m_{\text {Aga }+ \text { SNX: }} 10.95 \pm 2.35 \% ; n=8$ cells), and Figure $3 F$ illustrates the results of the same experiment in each of the OHCs tested $\left(m_{\mathrm{c}}=0.338 \pm 0.100, m_{\mathrm{Aga}}=0.095 \pm 0.019, m_{\mathrm{Aga}}+\mathrm{SNX}=0.036 \pm\right.$ $0.008 ; m_{\mathrm{c}}$ vs $m_{\mathrm{Aga}}, p=2 \times 10^{-5} ; m_{c}$ vs $m_{\mathrm{Aga}}+\mathrm{SNX}, p=6 \times 10^{-5}$; $m_{\text {Aga }}$ vs $m_{\text {Aga }+ \text { SNX }} p=2 \times 10^{-5}$; Kendall's $\mathrm{W}=1 ; n=8$ cells). The higher block exerted by SNX when applied alone ( $~ 58 \%)$, compared with that exerted by this toxin after blocking transmitter release with $\omega$-Aga-IVA $(\sim 26 \%)$, is similar to that reported for the effects of $\omega$-CgTx on transmitter release at the calyx of Held synapse whether applied before or after partially blocking this process with $\omega$-Aga-IVA (Iwasaki et al., 2000).

At P20-P22, the sequential application of $\omega$-Aga-IVA, $\omega-\mathrm{CgTx}$, and $\mathrm{Ni}^{2+}$ was not possible because, as shown in Figure $1 E$, recordings in voltage-clamped $\mathrm{OHCs}$ only remain stable for $30 \mathrm{~min}$, and this time is not enough to sequentially reach the steady-state effect exerted by each of the three VGCC blockers under study. The above results show that transmitter release at the onset of hearing (P11-P13) is mediated by $\mathrm{Ca}^{2+}$ entry through $\mathrm{P} / \mathrm{Q}$ - and R-type VGCCs, whereas at a more mature stage (P20-P22), in addition to P/Q- and R-type VGCCs, N-type VGCCs are also coupled to the release process. The late coupling of N-type VGCCs to ACh release is identical to that found during development at the transient MOC-IHC synapse (Kearney et al., 2019).

\section{The role of L-type VGCC in the release process at the MOC- OHC synapse at P11-P13 and P20-P22}

Under normal conditions, L-type VGCCs do not support transmitter release at fast synapses (Catterall, 2011). However, and in agreement with reports at reinnervating synapses (Katz et al., 1996) and developing synapses (Sugiura and Ko, 1997; Rosato Siri and Uchitel, 1999), we have recently shown that during the early periods of neonatal development of the transient mouse MOC-IHC synapse, $\mathrm{Ca}^{2+}$ entry through L-type VGCCs can, under certain circumstances, support transmitter release (Kearney et al., 2019).

L-type VGCCs are highly sensitive to micromolar concentrations of DHPs that, either negatively (i.e., nifedipine, nitrendipine) or positively (i.e., BayK), modulate their activity (Doering and Zamponi, 2003; Catterall and Few, 2008). Therefore, to study the role of L-type VGCCs in ACh release at the MOC$\mathrm{OHC}$ synapse during postnatal development, we tested the effects of nifedipine and BayK on $m$ at P11-P13 and P20-P22. We found that at P11-P13 both the agonist (10 $\mu \mathrm{M}$ BayK) and the antagonist

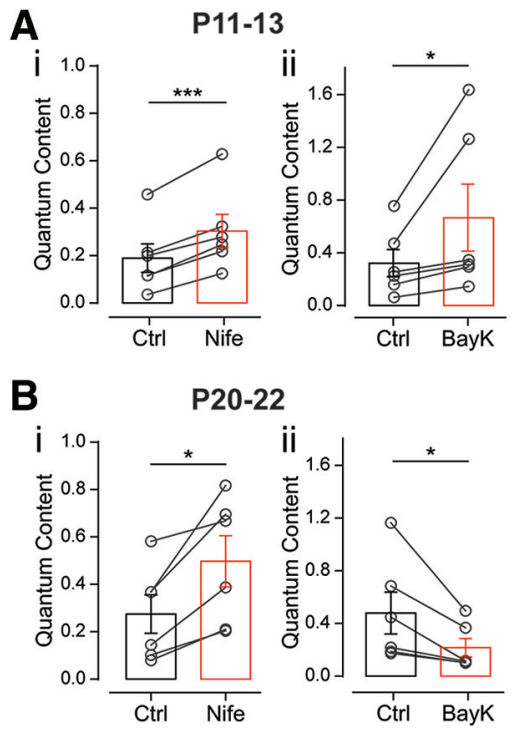

Figure 4. Differential effects of L-type VGCCs modulators at the MOC-OHC synapse during development. Ai,ii, Effect of $3 \mu \mathrm{m}$ Nife (i) and $10 \mu \mathrm{m}$ BayK (ii), antagonist and agonist of Ltype VGCCs, respectively, on the quantum content of transmitter release at P11-P13. $\boldsymbol{B}$, The same as $\boldsymbol{A}$ at P20-P22. Paired $t$ test or Wilcoxon rank sum test; ${ }^{*} p<0.05,{ }^{* * *} p<0.001$.

( $3 \mu \mathrm{M}$ nifedipine) caused a significant increment in the amount of transmitter released (Fig. $4 A ; m_{\mathrm{c}}=0.189 \pm 0.060, m_{\mathrm{Nife}}=$ $0.303 \pm 0.070 ; p=0.0004$, Hedge's $g=0.66 ; m_{c}=0.321 \pm 0.103$, $m_{\text {BayK }}=0.666 \pm 0.254, p=0.0313$, Wilcoxon's $r=0.62 ; n=6$ cells). At P20-P22, however, the agonist and the antagonist had opposing effects on release. Nifedipine caused a significant increment in release, while BayK caused a significant reduction of this parameter (Fig. $4 B ; m_{\mathrm{c}}=0.275 \pm 0.081, m_{\mathrm{Nife}}=0.497 \pm 0.108, p=0.0128$, Hedge's $g=0.88 ; m_{c}=0.479 \pm 0.159, m_{\text {BayK }}=0.216 \pm 0.070$, $p=0.0312$, Wilcoxon's $r=0.62 ; n=6$ cells). The results obtained with DHPs are identical to those found at the transient MOCIHC synapse, where, at the early periods of development (P4-P7), both BayK and nifedipine increase transmitter release (Kearney et al., 2019), whereas at P9-P11 BayK reduces and nifedipine increases this process (Zorrilla de San Martín et al., 2010). The apparently contradictory effects of DHPs at the MOC-IHC synapse were accounted for by the functional coupling of L-type VGCCs and BK channels that accelerate the repolarization of the terminal membrane and therefore reduce the amount of ACh released per action potential (Roberts et al., 1990; Robitaille et al., 1993b; Zorrilla de San Martín et al., 2010).

L-type VGCCs have been shown to be present both at presynaptic MOC terminals (Waka et al., 2003; Zorrilla de San Martín et al., 2010; Kearney et al., 2019) and also at postsynaptic hair cell membranes (Michna et al., 2003; Knirsch et al., 2007). Therefore, DHPs added to the bath solution would be targeting both presynaptic and postsynaptic L-type VGCCs. Notwithstanding, $\mathrm{Ca}^{2+}$ currents are very tiny, almost negligible in OHCs voltageclamped at $-40 \mathrm{mV}$, even when recorded in the presence of 10 $\mathrm{mm} \mathrm{Ba}^{2+}$ (Knirsch et al., 2007). However, Knirsch et al. (2007) have shown that BayK can significantly enhance these currents. In addition, it has been shown that in IHCs from P9 to P11 voltage clamped at $-40 \mathrm{mV}$, although $10 \mu \mathrm{M}$ BayK does not have any effect on eIPSC amplitudes, it significantly prolongs their decay time (Zachary et al., 2018). Therefore, to study whether there was any contribution of postsynaptic $\mathrm{Ca}^{2+}$ flowing in through L-type VGCCs to the cholinergic response, we evaluated eIPSC amplitudes and kinetics with and without BayK $(10 \mu \mathrm{M})$ 
in the bath solution. No significant differences between both conditions were found either at P11-P13 (eIPSC amplitude: $\mathrm{Ctrl}=32.74 \pm 4.02 \mathrm{pA}$, BayK $=38.38 \pm 4.24 \mathrm{pA}, \quad p=0.3346$; $\tau_{\text {rise: }} \quad \mathrm{Ctrl}=13.09 \pm 0.44 \mathrm{~ms}, \quad$ BayK $=15.46 \pm 1.68 \mathrm{~ms}, \quad p=0.2662$; $\tau_{\text {decay }}:$ Ctrl $=38.32 \pm 3.44 \mathrm{~ms}, \mathrm{BayK}=49.64 \pm 1.68 \mathrm{~ms}, p=0.2665, n=$ 6) or at P20-P22 (eIPSC amplitude: Ctrl $=42.28 \pm 10.77 \mathrm{pA}$, BayK $=33.33 \pm 3.79 \mathrm{pA}, \quad p=0.4762 ; \tau_{\text {rise }}: \quad \mathrm{Ctrl}=10.61 \pm 1.32$ $\mathrm{ms}, \mathrm{BayK}=13.19 \pm 0.77 \mathrm{~ms}, \quad p=0.2158 ; \tau_{\text {decay }}:$ Ctrl $=36.72 \pm$ $4.71 \mathrm{~ms}, \mathrm{BayK}=41.02 \pm 9.28 \mathrm{~ms}, p=0.4931 ; n=6)$. This lack of effect of BayK on eIPSCs parameters reinforces the notion that the observed effect of this drug on synaptic transmission at the MOC-OHC synapse can be solely accounted for by its effects on presynaptic L-type VGCCs.

\section{Coupling between L-type VGCCs and BK channels changes during maturation of the MOC-OHC synapse}

In view of the above presented results with DHPs at the MOC$\mathrm{OHC}$ synapse and taking into account previous work at the transient MOC-IHC synapse (Zorrilla de San Martín et al., 2010; Kearney et al., 2019), we first evaluated by electrophysiological and pharmacological methods whether BK channels were functionally expressed in MOC synaptic terminals at the two age groups under study. The BK channel blocker, IbTx (200 nM) significantly increased the amount of ACh released on MOC stimulation (Fig. 5A; P11-P13: $m_{\mathrm{c}}=0.129 \pm 0.010, m_{\mathrm{IbTx}}=$ $0.219 \pm 0.021, p=0.0043$, Hedge's $g=2.03 ; \mathrm{P} 20-\mathrm{P} 22: m_{\mathrm{c}}=$ $0.224 \pm 0.022, \quad m_{\mathrm{IbTx}}=0.376 \pm 0.046, p=0.0012$, Hedge's $\mathrm{g}=1.50 ; n=6-7$ cells). These results show that BK channels are functionally expressed at both age groups, suggesting that, as found at the MOC-IHC synapse (Zorrilla de San Martín et al., 2010; Kearney et al., 2019), $\mathrm{Ca}^{2+}$ flowing in through L-type VGCCs is fueling BK channels and therefore is blocking them with nifedipine leads to an increase in the amount of transmitter released at both age groups (Fig. 4). Interestingly, at P11-P13 BayK, which enhances the activity of L-type VGCCs (Hess et al., 1984), had the same effect as nifedipine, whereas at P20-P22 it reduced the number of $\mathrm{ACh}$ vesicles released per nerve impulse (see above; Fig. 4). To elucidate whether at P11-P13, apart from fueling BK channels, $\mathrm{Ca}^{2+}$ influx through L-type VGCCs could be contributing to ACh release as described at the MOC-IHC synapse at the early stages of development (Kearney et al., 2019), we conducted occlusion experiments in which we incubated the cochlear preparation with the BK channel antagonist $(200 \mathrm{nM}$ $\mathrm{IbTx}$ ) before applying either nifedipine or BayK to the bath solution. In the absence of functional BK channels due to the presence of IbTx, nifedipine $(3 \mu \mathrm{M})$ was unable to enhance the release of ACh at P11-P13 (Fig. $5 B i ; m_{\mathrm{c}}=0.233 \pm 0.062, m_{\mathrm{IbTx}}=$ $0.729 \pm 0.230, m_{\mathrm{IbTx}}+$ Nife $=0.803 \pm 0.257 ; n=5 ; m_{\mathrm{c}} \mathrm{vs}_{\mathrm{IbTx}}$, $p=0.007 ; m_{\mathrm{c}}$ vs $m_{\mathrm{IbTx}}+$ Nife, $p=0.001 ; m_{\mathrm{IbTx}}$ vs $m_{\mathrm{IbTx}}+$ Nife, $p=0.89 ; \eta^{2} \mathrm{p}=0.33$ ) or at P20-P22 (Fig. 5Bii; $m_{\mathrm{c}}=0.412 \pm$ $0.079, \mathrm{~m}_{\mathrm{IbTx}}=0.696 \pm 0.089, \mathrm{~m}_{\mathrm{IbTx}}+\mathrm{Nife}=0.674 \pm 0.099 ; n=5$; $\mathrm{m}_{\mathrm{c}}$ vs $\mathrm{m}_{\mathrm{IbTx}}, p=0.0003 ; \mathrm{m}_{\mathrm{c}}$ vs $\mathrm{m}_{\mathrm{IbTx}}+$ Nife, $p=0.0039 ; \mathrm{m}_{\mathrm{IbTx}}$ vs $\mathrm{m}_{\mathrm{IbTx}}+$ Nife, $p=0.081$; Kendall's $\left.\mathrm{W}=0.84\right)$. Under the same conditions, however, BayK $(10 \mu \mathrm{M})$ still significantly enhanced release at $\mathrm{P} 11-\mathrm{P} 13$ (Fig. $5 \mathrm{C} i ; m_{\mathrm{c}}=0.221 \pm 0.035, m_{\mathrm{IbTx}}=$ $0.468 \pm 0.114, \quad m_{\mathrm{IbTx}}+\mathrm{BayK}=0.682 \pm 0.154 ; n=7 ; m_{\mathrm{IbTx}}$ vs $m_{\mathrm{IbTx}+\text { BayK}}, p=0.0002 ; m_{\mathrm{c}}$ vs $m_{\mathrm{IbTx}+\mathrm{BayK}}, p=0.0006 ; m_{\mathrm{IbTx}}$ vs $m_{\mathrm{IbTx}+\mathrm{BayK}}, p=0.0002$; Kendall's $\mathrm{W}=1$ ), whereas at P20-P22 this DHP had no effect in the presence of the BK channel blocker (Fig. 5 Cii; $m_{\mathrm{c}}=0.351 \pm 0.029, m_{\mathrm{IbTx}}=0.527 \pm 0.057, m_{\mathrm{IbTx}}+$ BayK $=$ $0.521 \pm 0.057 ; n=6 ; m_{\mathrm{c}}$ vs $m_{\mathrm{IbTx}}, p=0.0003 ; m_{\mathrm{c}}$ vs $m_{\mathrm{IbTx}}+$ BayK, $p=0.0001 ; m_{\mathrm{IbTx}} \mathrm{vs}_{\mathrm{mlbTx}}+$ BayK,$\left.p=0.544 ; \eta^{2} \mathrm{p}=0.38\right)$.

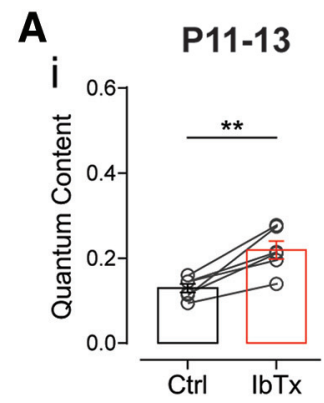

B

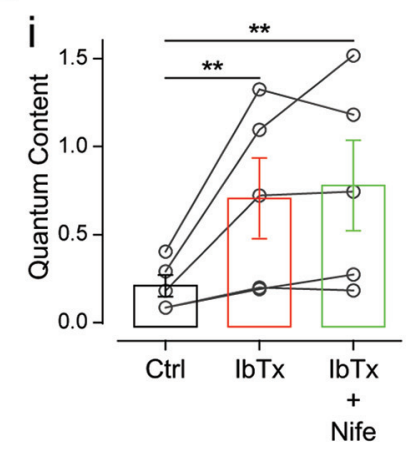

C

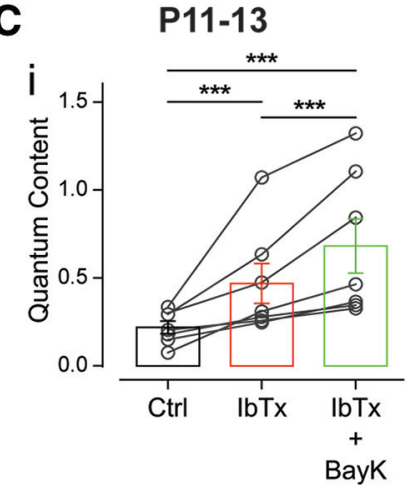

P20-22

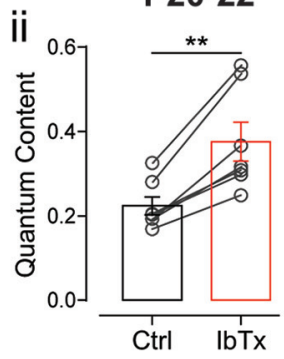

P20-22

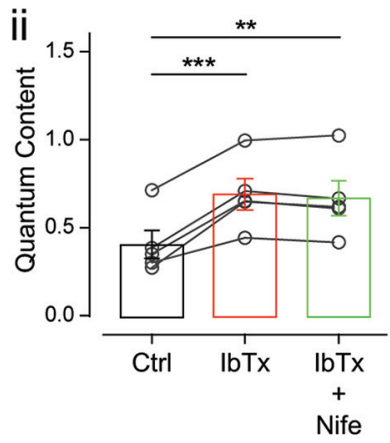

P20-22

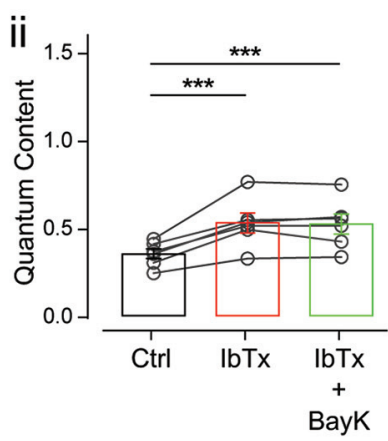

Figure 5. $\mathrm{Ca}^{2+}$ influx through L-type VGCCs fuel $\mathrm{Ca}^{2+}$-activated $\mathrm{K}^{+}$(BK) channels at the MOC-OHC synapse both at P11-P13 and P20-P22. Ai,ii, Effect on the quantum content of transmitter release of $200 \mathrm{~nm} \mathrm{IbTx}$, a specific blocker of BK channels, at P11-P13 (i) and P20-P22 (ii). Bi,ii, Effect of adding $3 \mu \mathrm{m}$ Nife on the quantum content of transmitter release in cochlear preparations at P11-P13 (i) and P20-P22 (ii) previously incubated with $200 \mathrm{~nm}$ $\mathrm{IbTx}$. Ci,ii, Effect of the sequential application of $200 \mathrm{~nm} \mathrm{IbTx}$ and $10 \mu \mathrm{m}$ BayK at P11-P13 (i) and P20-P22 (ii) on the quantum content of transmitter release. Paired $t$ test or Wilcoxon rank sum test in $\boldsymbol{A}$; repeated-measures ANOVA or Friedman test followed by Tukey's or Conover multiple-comparisons tests, respectively, for $\boldsymbol{B}$ and $\boldsymbol{C} ;{ }^{* *} p<0.01$, ${ }^{* * *} p<0.001$

The fact that IbTx completely occluded the effects of nifedipine and BayK at $\mathrm{P} 20-\mathrm{P} 22$ indicates that at this stage, $\mathrm{Ca}^{2+}$ influx through L-type VGCC is only involved in fueling BK channels, as described at the most mature stages of the transient MOC-IHC synapse (Zorrilla de San Martín et al., 2010). Noteworthy, at P11-P13 IbTx also prevented nifedipine from enhancing release, suggesting that under normal conditions the contribution of L-type VGCCs at the MOC-OHC synapse at the onset of hearing must be too small compared with that of P/Qand R-type VGCCs and, therefore, not sensitive to the application of the DHP antagonist. Together, these results suggest that at the onset of hearing, the negative feedback loop between Ltype VGCCs and BK channels might not be so tight (Zorrilla de San Martín et al., 2010; Kearney et al., 2019). Therefore, under certain conditions, as in the presence of BayK that prolongs L- 
type VGCCs mean open time (Hess et al., 1984), $\mathrm{Ca}^{2+}$ flowing in through these channels could also reach the release sites and contribute to triggering the release of ACh together with P/Q- and R-type VGCCs.

\section{The presynaptic components involved in ACh release are} scarcely compartmentalized at the onset of hearing We next investigated whether the differential effects of the Ltype VGCC agonist BayK had at P11-P13 and at P20-P22 could be accounted for by differences in the localization of VGCCs and $\mathrm{BK}$ channels at the MOC presynaptic terminals. Intracellular $\mathrm{Ca}^{2+}$ is a complex signal that can be shaped by factors that alter $\mathrm{Ca}^{2+}$ buffering and/or $\mathrm{Ca}^{2+}$ diffusion. Specifically, studies using intracellular $\mathrm{Ca}^{2+}$ chelators provide additional evidence in this respect and are effective tools for disrupting specific interactions between channels and synaptic proteins (Neher, 1998). Cell-permeant $\mathrm{Ca}^{2+}$ chelators, which become active intracellular $\mathrm{Ca}^{2+}$ buffers after the action of cytoplasmic esterases, are a noninvasive means of reducing the elevation of intracellular $\mathrm{Ca}^{2+}$, despite the fact that their final intracellular concentration is unknown (Tsien, 1981; Tymianski et al., 1994). We therefore evaluated the effects of IbTx and BayK in preparations from the two age groups under study that had been previously loaded with the cell-permeant slow $\mathrm{Ca}^{2+}$ chelator EGTA-AM. Treatment of different synaptic preparations with this slow buffer was shown to alter $\mathrm{Ca}^{2+}$ dynamics and disrupt synaptic facilitation without affecting the initial probability of release (Atluri and Regehr, 1996; Müller et al., 2010).

To evaluate the time needed to effectively load the OHCs with EGTA-AM $(100 \mu \mathrm{M})$, we monitored the facilitation index for P during paired-pulse stimulation protocols $\left(\mathrm{FI}=\mathrm{P}_{2} / \mathrm{P}_{1}\right)$ at $100 \mathrm{~Hz}$ (10 ms ISIs; see Materials and Methods). In agreement with previous reports at other synapses (Atluri and Regehr, 1996; Müller et al., 2010), facilitation (FI > 1) at the MOC-OHC synapse is abolished after 12.5 min of incubation with EGTA-AM, while the initial probability of release remained constant $\left(\mathrm{P}_{1}\right.$ : $\mathrm{Ctrl}=0.131 \pm 0.031$, EGTA $=0.111 \pm 0.024 ; n=6, p=0.252$; Fig. $6 A)$. The fact that facilitation was disrupted $\left(\mathrm{P}_{2} / \mathrm{P}_{1}: \mathrm{Ctrl}=2.055 \pm 0.238\right.$, EGTA $=0.794 \pm$ $0.113 ; n=6, p=0.004$, Hedge's $g=2.55$; Fig. $6 B i)$, but the quantum content was not altered by this treatment $(m$ : Ctrl $=0.144 \pm 0.038$, EGTA $=0.121 \pm 0.027 ; n=6, p=0.2613$; Fig. $6 \mathrm{Bii}$ ) indicates that after 12.5 min of incubation, the MOC synaptic terminals were successfully loaded with this $\mathrm{Ca}^{2+}$ chelator.

Under this condition (100 $\mu \mathrm{M}$ EGTA-AM), we studied the effects of IbTx and BayK at P11-P13 and P20-P22. At P11-P13, EGTA loading precluded IbTx and BayK from affecting transmitter release $\left(m_{\mathrm{c}}=0.110 \pm 0.017, m_{\mathrm{IbTx}}=0.107 \pm 0.094\right.$, $m_{\mathrm{IbTx}+\text { BayK }}=0.107 \pm 0.013 ; p=0.7454, n=5$ cells; Fig. $6 C$ ), whereas EGTA did not alter the effect of these drugs at P20-P22 $\left(m_{\mathrm{c}}=0.370 \pm 0.024, m_{\mathrm{IbTx}}=0.490 \pm 0.029, m_{\mathrm{EIbTx}+\mathrm{BayK}}=\right.$ $0.474 \pm 0.026 ; p=0.0001, \eta^{2} \mathrm{p}=0.53 ; n=5$ cells; Fig. $\left.6 D\right)$. At $\mathrm{P} 11-\mathrm{P} 13$, the slow $\mathrm{Ca}^{2+}$ chelator was able to interfere with the activation of BK channels by $\mathrm{Ca}^{2+}$ influx through L-type VGCCs (it occluded the increase in transmitter release observed on incubation with IbTx; Fig. 5Ai) and precluded $\mathrm{Ca}^{2+}$ influx from reaching the release sites on incubation with BayK (Fig. 4B). These results strongly suggest that at the onset of hearing, L-type VGCCs are not as close to BK channels as they are at P20-P22. In addition, they suggest that at P11-P13, L-type VGCCs are close enough so that $\mathrm{Ca}^{2+}$ influx through these channels can contribute to trigger release when their open probability is increased by BayK (Hess et al., 1984). Notwithstanding, the fact that the slow buffer EGTA was able to abolish the contribution of L-type VGCCs to evoked release indicates that this type of
A P11-13

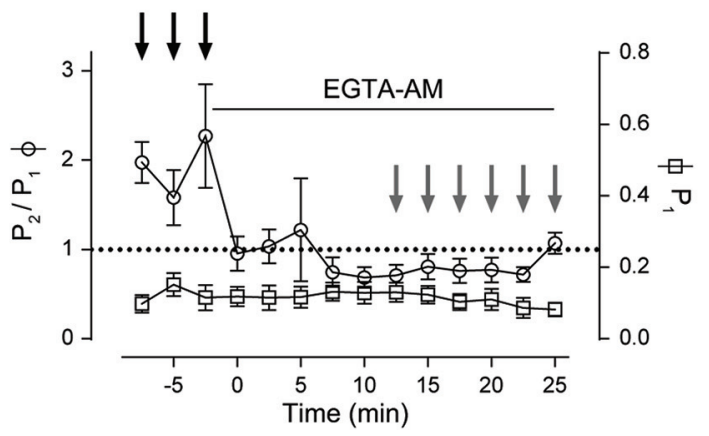

B

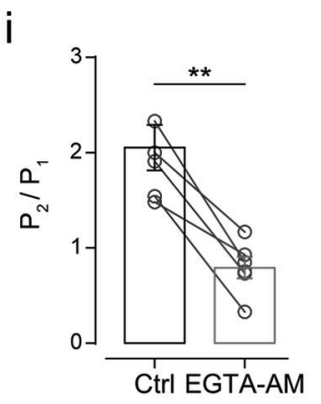

P11-13

C

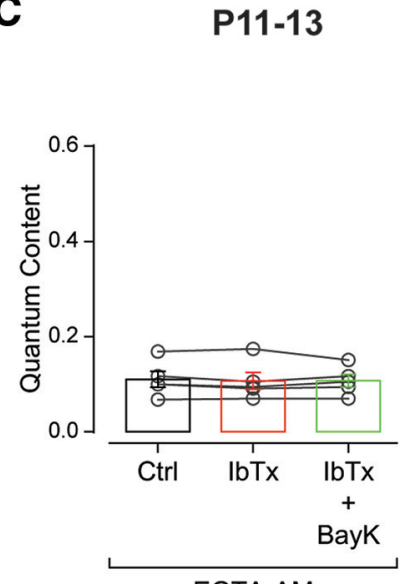

ii

D

P20-22

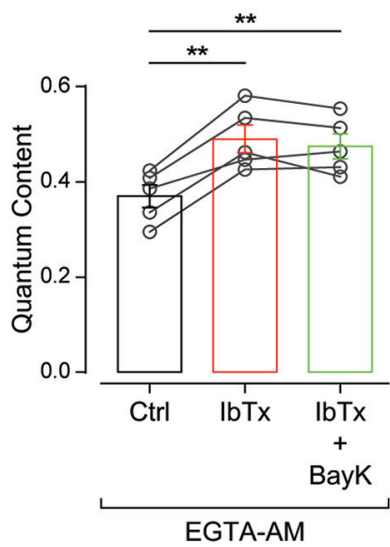

Figure 6. Scarce compartmentalization of the presynaptic components at the MOC terminals around the onset of hearing. $A$, Time course of the effect of $100 \mu \mathrm{m}$ EGTA-AM on the probability of release $\left(\mathrm{P}_{1}\right)$ and the facilitation index for the probability of release $\left(\mathrm{Fl}_{\mathrm{p}}=\right.$ $\left.P_{2} / P_{1}\right)$ during a paired-pulse protocol with a $10 \mathrm{~ms} I S I(100 \mathrm{~Hz})$. Bi,ii, Quantification of the effect of EGTA-AM on FIP (i) and the quantum content of transmitter release (ii). Values for each individual cell in Ctrl and EGTA-AM were averaged from the time points indicated with black and gray arrows in $\boldsymbol{A}$, respectively. C, D, Effect of the sequential application of $200 \mathrm{~nm}$ $\mathrm{IbTx}$ and $10 \mu \mathrm{m}$ BayK on the quantum content of transmitter release from P11-P13 $(C)$ and P20-P22 (D) mice in the presence of $100 \mu \mathrm{m}$ EGTA-AM. Paired $t$ test in $\boldsymbol{B}$; repeated-measures ANOVA for $\boldsymbol{C}$ and $\boldsymbol{D}$. ${ }^{* *} p<0.01$.

VGCCs is not as close to the release sites, as reported at other synapses mediated by P/Q-, N-, or R-type VGCCs where BAPTA, the fast $\mathrm{Ca}^{2+}$ buffer, but not EGTA can disrupt transmitter release (Wu et al., 1999; Rosato-Siri et al., 2002; Timmermann et al., 2002; Catterall, 2011; Eggermann et al., 2011).

The role of BK channels in synaptic plasticity at the MOC-OHC synapse around the onset of hearing

The results presented so far show that in addition to the changes in the types of VGCCs coupled to the release process, maturation 


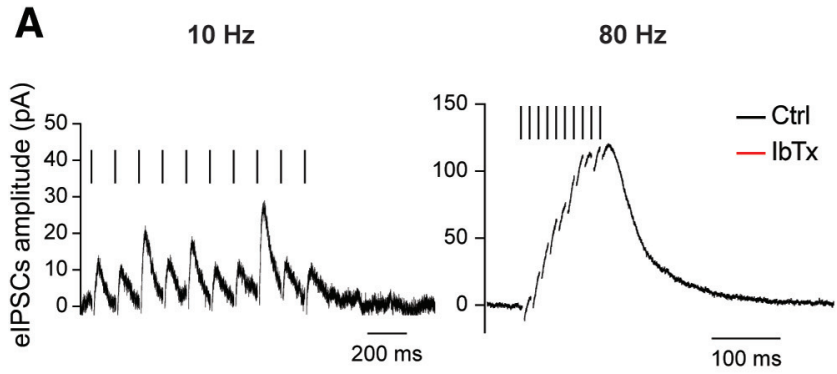

B
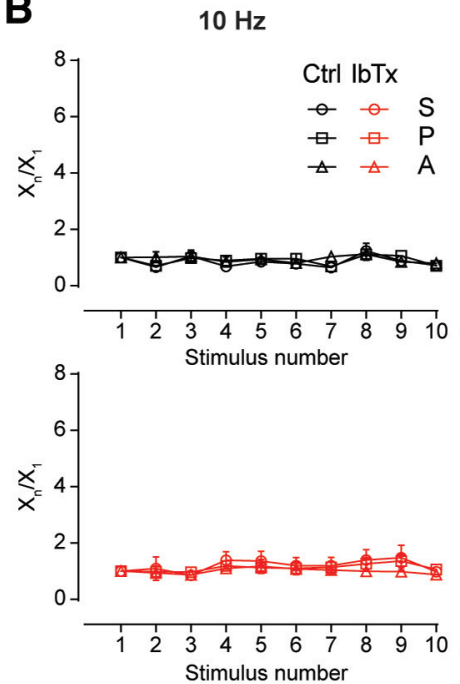

$80 \mathrm{~Hz}$
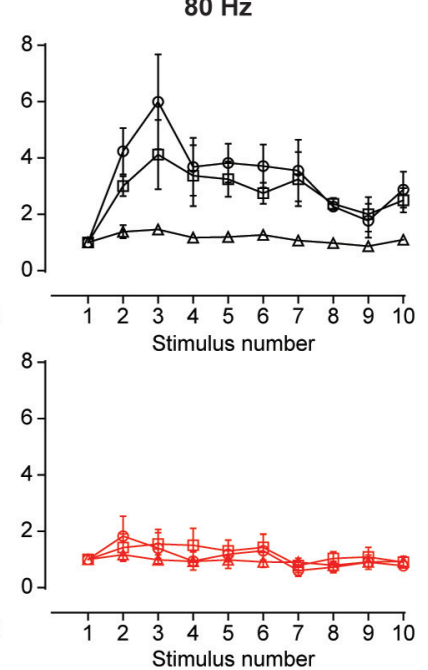

Figure 7. At around the onset of hearing, short-term synaptic facilitation during high-frequency stimulation is abolished by blocking $\mathrm{Ca}^{2+}$-activated BK channels. $A$, Representative averaged traces of 10 individual synaptic responses in P11-P13 OHCs on a $10 \mathrm{~Hz}$ (left) or $80 \mathrm{~Hz}$ (right) 10-pulse train stimulation protocol in the absence (top) or the presence (bottom) of $200 \mathrm{~nm} \mathrm{IbTx.}$ For clarification purposes, artifacts were removed and bars over traces indicate the corresponding stimulation pattern. $\boldsymbol{B}$, The $\mathrm{S}, \mathrm{P}$, and the elPSC average A were computed for every pulse during 10-shock trains at frequencies of $10 \mathrm{~Hz}$ (left) and $80 \mathrm{~Hz}$ (right). The normalized mean values for these parameters at the two stimulation frequencies are plotted against the pulse number protocol in the absence (top) or the presence (bottom) of $200 \mathrm{~nm} \mathrm{IbTx}$. $10 \mathrm{~Hz}: n=4$ for (trl and $n=4$ for $200 \mathrm{~nm} \mathrm{IbTx;} 80 \mathrm{~Hz}$ : $n=6$ for Ctrl and $n=6$ for $200 \mathrm{~nm} \mathrm{IbTx}$. See Table 4 for quantification.

Table 4. Calculation of $\mathrm{FI}_{\mathrm{X}}=\mathrm{X}_{\mathrm{n}} / \mathrm{X}_{1}$ for $\mathrm{S}, \mathrm{P}$, and $\mathrm{A}$ at the MOC-OHC synapse, in the presence of $200 \mathrm{nM} \mathrm{IbTx}$

\begin{tabular}{|c|c|c|c|c|c|c|}
\hline & $\begin{array}{l}\text { Ctrl } \\
(n=4)\end{array}$ & & & $\begin{array}{l}\mathrm{lbTx} \\
(n=4)\end{array}$ & & \\
\hline $10 \mathrm{~Hz}$ & $\begin{array}{l}\mathrm{Fl}_{\mathrm{S}}=\mathrm{S}_{8} / \mathrm{S}_{1} \\
1.23 \pm 0.28 \\
(n=6)\end{array}$ & $\begin{array}{l}\mathrm{Fl}_{\mathrm{P}}=\mathrm{P}_{8} / \mathrm{P}_{1} \\
1.10 \pm 0.19\end{array}$ & $\begin{array}{l}\mathrm{Fl}_{\mathrm{A}}=\mathrm{A}_{8} / \mathrm{A}_{1} \\
1.12 \pm 0.13\end{array}$ & $\begin{array}{l}\mathrm{Fl}_{\mathrm{S}}=\mathrm{S}_{8} / \mathrm{S}_{1} \\
1.40 \pm 0.38 \\
(n=6)\end{array}$ & $\begin{array}{l}\mathrm{Fl}_{\mathrm{P}}=\mathrm{P}_{8} / \mathrm{P}_{1} \\
1.26 \pm 0.22\end{array}$ & $\begin{array}{l}\mathrm{Fl}_{\mathrm{A}}=\mathrm{A}_{8} / \mathrm{A}_{1} \\
1.00 \pm 0.14\end{array}$ \\
\hline $80 \mathrm{~Hz}$ & $\begin{array}{l}\mathrm{Fl}_{\mathrm{S}}=\mathrm{S}_{3} / \mathrm{S}_{1} \\
4.98 \pm 1.82^{*}\end{array}$ & $\begin{array}{l}F l_{p}=P_{3} / P_{1} \\
4.13 \pm 1.22^{*}\end{array}$ & $\begin{array}{l}\mathrm{Fl}_{\mathrm{A}}=\mathrm{A}_{3} / \mathrm{A}_{1} \\
1.46 \pm 0.15\end{array}$ & $\begin{array}{l}\mathrm{Fl}_{\mathrm{S}}=\mathrm{S}_{2} / \mathrm{S}_{1} \\
1.84 \pm 0.70\end{array}$ & $\begin{array}{l}\mathrm{Fl}_{\mathrm{p}}=\mathrm{P}_{2} / \mathrm{P}_{1} \\
1.42 \pm 0.48\end{array}$ & $\begin{array}{l}\mathrm{Fl}_{\mathrm{A}}=\mathrm{A}_{2} / \mathrm{A}_{1} \\
1.17 \pm 0.15\end{array}$ \\
\hline
\end{tabular}

Paired $t$ test or Wilcoxon rank sum test; ${ }^{*} p<0.05$.

of the MOC-OHC synapse also involves changes in the localization of the presynaptic components making up the release machinery. These changes were observed on the two proteins that make up the negative feedback loop, namely, L-type VGCCs and BK channels, whose proximity, as judged by the experiments in the presence of EGTA-AM (Fig. 6), seems to increase between P11-P13 and P20-P22. Notwithstanding, even at the onset of hearing, the negative feedback loop is already functional as blocking BK channels with IbTx caused a quite significant increase in ACh release (Fig. 5A).

Bearing in mind that BK channels have been shown to be significantly relevant in controlling action potential firing at high frequencies ( $\mathrm{Gu}$ et al., 2007) and considering that in vivo MOC fibers fire at frequencies ranging from 1 to $120 \mathrm{~Hz}$ (Robertson and Gummer, 1985; Liberman and Brown, 1986; Atluri and Regehr, 1996; Müller et al., 2010), we investigated whether BK channels are involved in signaling at the MOC-OHC synapse during high-frequency activity of the MOC fibers. Because of technical reasons, mainly in obtaining stable and reproducible recordings during high-frequency stimulation trains at P20-P22, the following experiments were only performed at MOC-OHC synapses from P11-P13 mice. We first evaluated the role of these channels in the STP properties of this synapse. To this end, we applied 10-pulse trains at 10 and $80 \mathrm{~Hz}$ in the absence or presence of IbTx (200 nM). Representative responses of the OHCs to those trains are illustrated in Figure $7 A$. To analyze the behavior of the MOC-OHC synapse during the stimulation train, we used the FI, as has already been done to evaluate the paired-pulse experiments illustrated in Figure 2. The $\mathrm{S}$ parameter (the average amplitude of postsynaptic responses including release failures) was evaluated after each of the 10 stimuli, and $\mathrm{FI}_{\mathrm{S}}$ was defined as the ratio between the $S$ value corresponding to the pulse in which the difference with respect to this value in the first pulse was maximal $\left(S_{n}\right.$ and $S_{1}$, respectively; $\left.F_{S}=S_{n} / S_{1}\right)$. Therefore, the parameters $\mathrm{P}$ (probability of successfully evoking a release event) and $\mathrm{A}$ (average amplitude of successfully evoked IPSCs) were analyzed to evaluate the presynaptic or postsynaptic origin of STP (Goutman et al., 2005; Ballestero et al., 2011; Fioravante and Regehr, 2011). $\mathrm{FI}_{\mathrm{P}}$ and $\mathrm{FI}_{\mathrm{A}}$, respectively, were defined for the same pulses used to define $\mathrm{FI}_{S}$. In agreement with the results obtained in the pairedpulse experiments (Fig. 2A,B, top panels) and with previous reports (Ballestero et al., 2011), the MOC-OHC synapse at the onset of hearing (P11-P13) only presented facilitation of responses on high-frequency stimulation $(80 \mathrm{~Hz})$ of the MOC fibers (Table 4, Fig. $7 B$, top panels; $\mathrm{FI}_{\mathrm{S}-\mathrm{Ctrl}}: 10 \mathrm{~Hz}, p=0.74$; and $80 \mathrm{~Hz}, p=0.025$, Hedge's $g=1.63, n=4-6$ cells). As previously reported, changes in $\mathrm{FI}_{\mathrm{S}}$ at $80 \mathrm{~Hz}$ were followed by changes in $\mathrm{FI}_{\mathrm{P}}$ and not in $\mathrm{FI}_{\mathrm{A}}$, indicating a clear presynaptic origin for facilitation (Table 4, Fig. $7 B$, top; $\mathrm{FI}_{\mathrm{P}-\mathrm{Ctrl}}$ : $10 \mathrm{~Hz}, p=0.99 ; 80 \mathrm{~Hz}, p=0.0220$; Hedge's $\mathrm{g}=3.11$; $\left.\mathrm{FI}_{\mathrm{A}-\mathrm{Ctrl}} \mathrm{1} 10 \mathrm{~Hz}, p=0.52 ; 80 \mathrm{~Hz}, p=0.28\right)$. In the presence of $200 \mathrm{nM}$ IbTx, facilitation at $80 \mathrm{~Hz}$ was completely abolished. At $10 \mathrm{~Hz}$, however, the behavior of the MOC-OHC synapse was not 
different from that observed in the control condition without IbTx (Table 4, Fig. 7B, bottom panels; $\mathrm{FI}_{\mathrm{S}-\mathrm{IbTx}}$ : $10 \mathrm{~Hz}, p=0.95 ; 80$ $\mathrm{Hz}, p=0.87 ; \mathrm{FI}_{\mathrm{P}-\mathrm{IbTx}}: 10 \mathrm{~Hz}, p=0.71 ; 80$ $\mathrm{Hz}, p=0.55 ; \mathrm{FI}_{\mathrm{A}-\mathrm{IbTx}}: 10 \mathrm{~Hz}, p=0.78$; $80 \mathrm{~Hz}, p=0.74 ; n=4-6$ cells). These results are consistent with the fact that blocking BK channels causes a dramatic increment in the quantum content of evoked release at this synapse (Fig. 5A). This increment in synaptic strength was also evidenced by the higher amplitude of synaptic responses in the presence of IbTx, which can be easily observed during the $10 \mathrm{~Hz}$ train (Fig. $7 A$, bottom). The increment in the initial probability of release is usually accompanied by a decrease in short-term facilitation (Murthy et al., 1997; Fioravante and Regehr, 2011; Kearney et al., 2019). This notion is in accordance with the present results.

Although the above results show that BK channels participate in signaling at the MOC-OHC synapse, the short stimulation protocols used to study the STP pattern do not necessarily represent the physiological behavior of this synapse. Considering that the in vivo firing frequency of the MOC fibers increases with the intensity of sound stimulation and that this response is part of the olivocochlear reflex that is activated by sounds of variable duration (Galambos, 1956; Wiederhold and Kiang, 1970; Gifford and Guinan, 1987; Brown, 1989; Guinan, 2011), it is expected that MOC fibers would normally fire for longer periods than that encompassed by a 10-pulse train. In addition, auditory function inhibition by MOC activity has been shown to last for as long as MOC fibers are stimulated and to decay within hundreds of milliseconds (Wiederhold and Kiang, 1970; Guinan, 1996). Moreover, it has also been shown that the MOC-OHC synapse is able to sustain release on high-frequency firing of the MOC fibers for long periods (Ballestero et al., 2011). Therefore, to further investigate the role of presynaptic BK channels in signaling at this synapse, we tested the effects of blocking these channels during 50-pulse high-frequency stimulation trains. Representative recordings at these two frequencies in the presence (Fig. 8, top panels) or absence of functional BK channels are shown in Figure 8. At a first glance, it can be observed that the current traces obtained at $10 \mathrm{~Hz}$ in the presence of 200 nM IbTx (Fig. 8A, left bottom) showed greater synaptic activity compared with those obtained in the absence of the BK channel blocker (Fig. $8 A$, left top), which $\begin{array}{lll}\text { A } & 10 \mathrm{~Hz} & 80 \mathrm{~Hz}\end{array}$
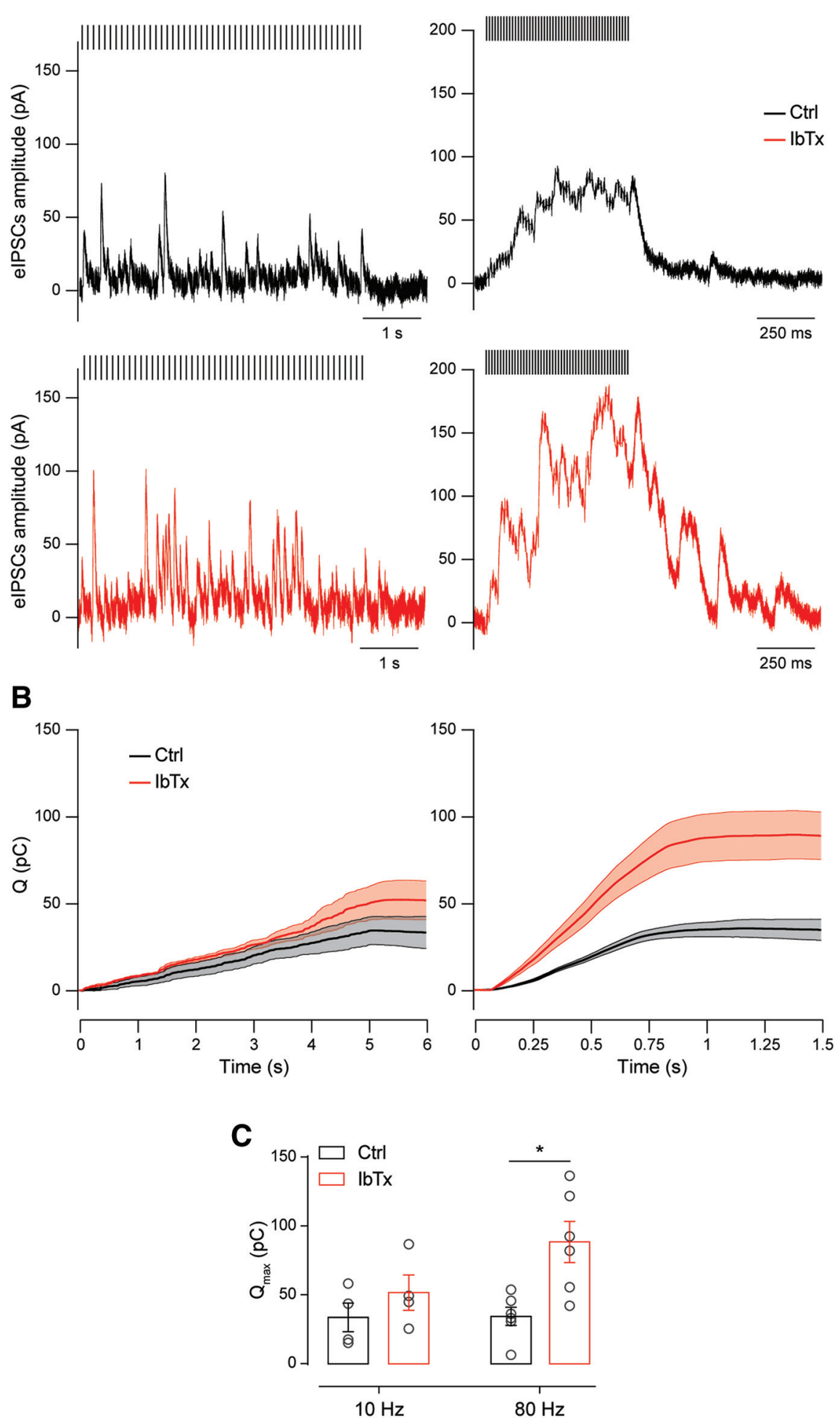

Figure 8. Around the onset of hearing, presynaptic $\mathrm{Ca}^{2+}$-activated BK channels limit the $\mathrm{OHC}$ output current during highfrequency stimulation of the MOC fibers. $\boldsymbol{A}$, Representative traces of single synaptic responses in P11-P13 OHCs on a $10 \mathrm{~Hz}$ (left) or $80 \mathrm{~Hz}$ (right) 50-pulse train stimulation protocol in the absence (top) or the presence (bottom) of $200 \mathrm{~nm} \mathrm{IbTx.} \mathrm{For}$ clarifying purposes, stimulation artifacts were replaced by bars over the traces. $\boldsymbol{B}$, Average $Q$ plotted as a function of time during $10 \mathrm{~Hz}$ (left) or $80 \mathrm{~Hz}$ (right) 50-pulse train stimulation protocols. Thick lines indicate mean values, while thin lines and the shaded area represent \pm SEM $C$, Average $Q_{\max }$ corresponding to the maximum value reached in $\boldsymbol{B}$ at the end of the 50 pulse train stimulation protocols, for both 10 and $80 \mathrm{~Hz}$ stimulation frequencies. Unpaired $t$ test. ${ }^{*} p<0.05$. 
is consistent with the increment in the quantum content in the presence of this antagonist (Fig. $5 A$ ). At $80 \mathrm{~Hz}$, the response in the absence of IbTx is homogenous and sustained (Fig. 8A, right top) as was previously reported (Ballestero et al., 2011). Conversely, in the presence of the BK channel blocker, synaptic activity at $80 \mathrm{~Hz}$ becomes more erratic (Fig. $8 A$, right bottom), probably due to the lack of the negative feedback control exerted by BK channel activation on depolarization of the terminal membrane (Zorrilla de San Martín et al., 2010). In addition, the postsynaptic response maximal amplitude in the absence of functional BK channels was higher than that of controls (Ctrl, 77.02 \pm 8.24 pA; IbTx, $158.70 \pm$ $20.71 \mathrm{pA} ; n=6$; Mann-Whitney test, $p=0.0022$; Wilcoxon's $r=0.89$ ), probably due to an enhancement of the efficacy of ACh release due to both presynaptic facilitation and postsynaptic summation already described during repetitive high-frequency stimulation at this synapse (Ballestero et al., 2011).

Upon evaluation of the charge transferred along the stimulation protocol, we found that at a frequency of $10 \mathrm{~Hz}$, there were no significant differences in the total charge accumulated in the control condition with respect to that in the presence of the BK channel blocker (Fig. $8 B$, left, C). At $80 \mathrm{~Hz}$, however, there was a significant increment in the total charge transferred during the stimulation train in the presence of $200 \mathrm{~nm} \mathrm{IbTx}$ (Fig. $8 B$, right, $C)$. Consistently, the maximal charge transferred $\left(\mathrm{Q}_{\max }\right)$, which was evaluated at the end of the stimulation protocol was only significantly higher in the presence of the $\mathrm{BK}$ channel blocker at $80 \mathrm{~Hz}$ (Fig. 8C; $10 \mathrm{~Hz}$ : $\mathrm{Q}_{\max -\mathrm{Ctrl}}=33.28 \pm 1.68 \mathrm{pC}$; $\mathrm{Q}_{\max -\mathrm{IbTx}}=$ $51.84 \pm 12.84 \mathrm{pC} ; n=4$ cells; $p=0.31 ; 80 \mathrm{~Hz}: \mathrm{Q}_{\max -\mathrm{Ctrl}}=$ $34.55 \pm 6.59$ pC; $\mathrm{Q}_{\max -\mathrm{IbTx}}=88.64 \pm 14.96 \mathrm{pC} ; n=6 ; p=0.0130$; Hedge's $g=1.76$ ). These results confirm that presynaptic BK channels play an important role in signaling at the MOC-OHC synapse.

Following the same rationale, we evaluated the impact that BK channel blockade exerts on the magnitude of the hyperpolarization observed in the OHCs during prolonged high-frequency stimulation. To this end, we held the OHCs under current clamp while applying a 50-pulse stimulation protocol at $80 \mathrm{~Hz}$ and analyzed the effect of $200 \mathrm{~nm}$ IbTx on the OHC membrane potential during the train (Fig. 9A). Under these conditions, significant differences were observed in the maximal hyperpolarization $\left(\Delta V_{\max }\right)$ reached during the train (Fig. $9 B ; \Delta V_{\max -\mathrm{Ctrl}}=$ $4.62 \pm 0.78 \mathrm{mV} ; \Delta V_{\max -\mathrm{IbTx}}=9.85 \pm 1.37 \mathrm{mV} ; n=5-6$ cells; $p=0.0120$; Hedge's $g=1.70$ ) and in the time necessary for the membrane potential to return to its basal value $\left(\Delta t_{\text {base }}\right)$ in the presence and absence of IbTx (Fig. $8 C ; \Delta \mathrm{t}_{\text {base-Ctrl }}=0.22 \pm 0.02 \mathrm{~s}$; $\Delta \mathrm{t}_{\text {base-IbTx }}=0.48 \pm 0.07 \mathrm{~s} ; n=5-6$ cells; $p=0.0160$; Hedge's $\mathrm{g}=$ 1.68). This latter result is consistent with the voltage-clamp experiments shown above where it can be observed that in the presence of the BK channel blocker, there is an asynchronous activity that outlasts the end of the stimulation train (Fig. 8A). These results confirm that at the onset of hearing $\mathrm{BK}$ channels provide a negative control mechanism at the MOC-OHC synapse. It is important to note that this mechanism is relevant even at this early stage when presynaptic components are scarcely compartmentalized, as evidenced by the fact that the slow $\mathrm{Ca}^{2+}$ buffer EGTA was able to interfere with the activation of $\mathrm{BK}$ channels by $\mathrm{Ca}^{2+}$ influx through L-type VGCCs (Fig. 6C). Therefore, at P20-P22 this negative control mechanism would probably be even more robust since at this mature stage $\mathrm{BK}$ channels and L-type VGCCs are more tightly coupled (Fig. 6D).

Together, these results suggest that this mechanism is particularly relevant to high-frequency MOC fiber firing rate, in
A

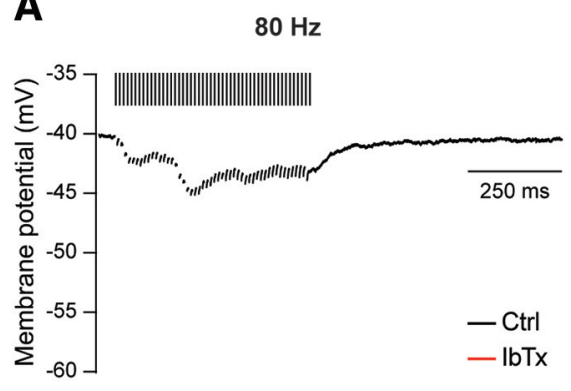

B $\square$ Ctrl

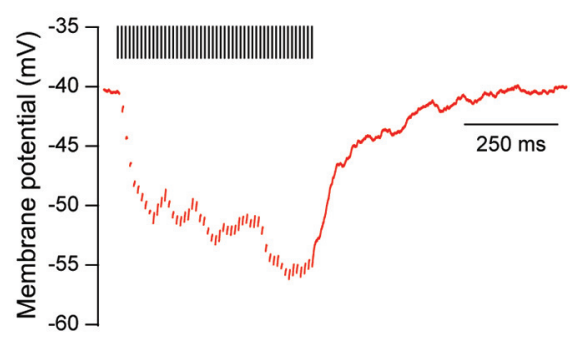

Figure 9. Presynaptic $\mathrm{Ca}^{2+}$-activated BK channels control the degree of hyperpolarization on high-frequency stimulation of the MOC fibers. $\boldsymbol{A}$, Representative traces of $\mathrm{OHCS}$ recorded in the current-clamp configuration on a $80 \mathrm{~Hz} 50$-pulse train stimulation protocol in the absence (top) or the presence (bottom) of $200 \mathrm{~nm} \mathrm{IbTx}$. For clarifying purposes, stimulation artifacts were replaced by bars over the traces. $\boldsymbol{B}, \boldsymbol{C}$, Effect of $200 \mathrm{~nm} \mathrm{IbTx}$ on the maximal change of the membrane potential $\left(\Delta V_{\max } ; \boldsymbol{B}\right)$ and the time required to return to baseline membrane potential after the end of the stimulation protocol ( $\Delta t$ after train; $\boldsymbol{C}$. Unpaired $t$ test for $\boldsymbol{B}$ and $\boldsymbol{C} ;{ }^{*} p<0.05$.

agreement with previous reports pointing to BK channels as fundamental elements in the control of presynaptic action potential firing frequency ( $\mathrm{Hu}$ et al., 2001; Klyachko et al., 2001; Gu et al., 2007).

\section{Discussion}

The MOC-OHC synapse has a fundamental role in hearing as it is the effector of the MOC reflex on the organ of Corti (Guinan, 2011), and its synaptic properties are crucial to determine the efficacy of this feedback to the cochlea (Ballestero et al., 2011; Wedemeyer et al., 2018). During development, the organ of Corti undergoes dramatic changes in the afferent and efferent innervation to the hair cells, which ultimately determine the correct function of this sensory epithelium in adult animals (Simmons, 2002; Bulankina and Moser, 2012). In this work, we studied the properties of transmitter release and the ion channels coupled to this process at the efferent MOC-OHC synapse at $\mathrm{P} 11-\mathrm{P} 13$, around hearing onset, and at P20-P22, the stage at which the mouse peripheral auditory system has already matured.

\section{Transmitter release properties, synaptic strength, and STP} pattern during MOC-OHC synapse maturation

In altricial rodents, MOC fibers start to innervate the OHCs during the second postnatal week (Dulon et al., 1998; He and Dallos, 1999; Simmons, 2002; Roux et al., 2011). Accordingly, we found a progressive increase in the number of functional MOC-OHC synapses, as well as in their strength and efficacy during maturation. At hearing onset, the MOC-OHC synapse presented facilitation during MOC fiber high-frequency stimulation, which, consistent with the increment in synaptic strength (Fioravante and Regehr, 2011; Jackman and Regehr, 2017), disappeared on maturation. Similar modifications in STP patterns were reported at the MOC-IHC synapse (Kearney et al., 2019) and at some 
CNS synapses, namely, in the cerebellum (Pouzat and Hestrin, 1997), hippocampus (Schiess et al., 2010) and the Calyx of Held (Taschenberger and von Gersdorff, 2000). At the MOC-IHC synapse, changes in synaptic strength and STP pattern correlate with RRP (Readily releasable pool) size and replenishment rate increments (Kearney et al., 2019). This has also been reported at the Calyx of Held (Iwasaki and Takahashi, 2001); therefore, a similar process might take place at the MOC-OHC synapse during maturation. Changes in synaptic efficacy and STP patterns could be also accounted for by modifications in the proteins mediating vesicle fusion (Kochubey et al., 2016). Alternatively, the proteins controlling presynaptic VGCC function could undergo modifications. $\mathrm{P} /$ Q-type VGCCs have been shown to contribute either to mechanisms of short-term facilitation or depression depending on the presynaptic regulatory proteins associated with them (Nanou and Catterall, 2018). Moreover, regulation of the number of VGCCs expressed at the presynaptic terminals could determine synaptic strength and thus the plasticity properties of a synapse (Sheng et al., 2012). In accordance with the prevailing view on this issue (Jackman and Regehr, 2017), we show that the factors underlying facilitation at the MOC-OHC synapse at P11P13 are of presynaptic origin, as previously described (Ballestero et al., 2011). At this age, the combined effect of facilitation and summation was shown to result in a frequency-dependent increase in the eIPSC amplitude of OHC, indicating that STP is responsible for shaping MOC inhibition (Ballestero et al., 2011). Although facilitation disappears at P20-P22, the increment in synaptic transmission reliability and the fact that no changes were observed in eIPSC kinetics support the idea that at this stage summation of eIPSCs on MOC high-frequency activity in response to high-level sounds would determine the strength of MOC inhibition and, therefore, the gain of the cochlear amplifier.

\section{Changes in the VGCC types coupled to ACh release during MOC-OHC synapse maturation}

The following two main changes were found regarding the VGCC coupled to transmitter release at the MOC-OHC synapse: the participation of N-type VGCCs at P20-P22 but not at hearing onset; and that at this early stage, $\mathrm{Ca}^{2+}$ influx through Ltype VGCCs can reach the exocytotic sites and trigger release together with P/Q- and R-type VGCCs (Fig. 10). These changes in the VGCC types coupled with ACh release are consistent with reports at the neuromuscular junction (Rosato Siri and Uchitel, 1999) and at some CNS synapses (Iwasaki and Takahashi, 1998; Iwasaki et al., 2000; Momiyama, 2003; Fedchyshyn and Wang, 2005). Noteworthy, however, contrary to what has been reported at those synapses, at the MOC-OHC synapse P/Q-type VGCCs contribute to triggering release before $\mathrm{N}$-type VGCCs participation. The late involvement of N-type VGCCs to ACh release has also been reported at the transient MOC-IHC synapse (Kearney et al., 2019). Interestingly, at both synapses the contribution of P/ Q-type VGCCs persists along the studied periods. This suggests that this VGCC type is more efficiently coupled to transmitter release, as reported at other synapses (Rosato Siri and Uchitel, 1999; Wu et al., 1999). In addition, a differential contribution of P/ Q- and N-type VGCCs to STP has been described at GABAergic cortical synapses. At those synapses, facilitation and depression of IPSCs mediated by P/Q-type and N-type VDCCs, respectively, were observed (Yamamoto and Kobayashi, 2018). Moreover, during development of the Calyx of Held there is an increment in the expression of $\mathrm{P} / \mathrm{Q}$-type VGCCs and a reduction in the expression of N-type VGCCs with a concomitant reduction in short-term depression (Iwasaki and Takahashi, 1998; Iwasaki et al., 2000; Taschenberger and von Gersdorff, 2000).

As mentioned above, facilitation of eIPSCs on high-frequency stimulation is no longer observed as the MOC-OHC synapse matures. Considering that facilitation and depression mechanisms coexist and therefore the postsynaptic current size depends on the short-term history of presynaptic activity (Zucker and Regehr, 2002; Fioravante and Regehr, 2011), the involvement of N-type VGCCs in transmitter release at P20-P22 might compensate for P/Q-type VGCC-mediated facilitation. Interestingly, at the MOC-IHC synapse, this change in the contribution of N-type VGCCs to ACh release on maturation is accompanied by a shift from facilitation at $\mathrm{P} 4$, when only $\mathrm{P} / \mathrm{Q}$ and R-type VGCCs are coupled to transmitter release, to depression at P9-P11 when both P/Q- and N-type VGCCs contribute to this process (Kearney et al., 2019). At the MOC-OHC synapse, however, R-type VGCCs continue being functional at mature stages and, together with P/Q- and N-type VGCCs, support transmitter release. The persistence of R-type VGCCs at the MOC-OHC synapse mature stages agrees with reports using RT-PCR (Green et al., 1996) and with studies showing their localization at the base of the OHCs (Waka et al., 2003). Moreover, at hippocampal synapses, R-type VGCCs have an increased contribution to synaptic transmission at frequencies $>1 \mathrm{~Hz}$ compared with P/Q and N-type VGCCs (Ricoy and Frerking, 2014). The participation of R-type VGCCs could be particularly relevant at MOC-OHC synapses when MOC fibers 
fire at high frequencies in response to high-intensity sounds (Galambos, 1956; Wiederhold and Kiang, 1970; Gifford and Guinan, 1987). This could be directly related to the ability of the MOC pathway to regulate the gain of the auditory system, which is fundamental for noise protection (Liberman, 1991; Rajan, 2000; Maison et al., 2002; Taranda et al., 2009; Boero et al., 2018).

\section{The role of L-type VGCCs and BK channels at the MOC- OHC synapse}

The present results show that the functional coupling of $\mathrm{Ca}^{2+}$ influx through L-type VGCCs to the activation BK channels regulates synaptic strength at the MOC-OHC synapse at both stages (Fig. 10). The functional coupling of VGCCs to BK channel activation (Marrion and Tavalin, 1998; Vergara et al., 1998; Grunnet and Kaufmann, 2004; Womack et al., 2004; Vivas et al., 2017) and their role in negatively regulating transmitter release have been previously described (Roberts et al., 1990; Robitaille et al., 1993a,b; Raffaelli et al., 2004; Zorrilla de San Martín et al., 2010; Deng et al., 2013).

At hearing onset, L-type VGCCs at the MOC-OHC synapse, apart from activating $\mathrm{BK}$ channels can contribute to trigger $\mathrm{ACh}$ release. This dual and antagonistic role of $\mathrm{Ca}^{2+}$ influx has been demonstrated for L-type VGCCs at the MOC-IHC synapse early stages (Kearney et al., 2019) and for N-type VGCCs at the frog neuromuscular junction (Robitaille et al., 1993a,b). In addition, at P11-P13, but not at P20-P22, the $\mathrm{Ca}^{2+}$ buffer EGTA disrupts the functional coupling between L-type VGCCs and BK channels, indicating that at hearing onset the distance between these channels is greater than at more mature stages. Moreover, at P11-P13 this slow buffer also eliminates the direct contribution of L-type VGCCs to ACh release. These results suggest that during MOC-OHC synapse maturation compartmentalization of exocytotic machinery components increases. A similar developmental tightening of presynaptic components involved in transmitter release has been reported at central synapses. (Iwasaki and Takahashi, 2001; Taschenberger et al., 2002; Fedchyshyn and Wang, 2005; Baur et al., 2015; Nakamura et al., 2015).

Multiple evidences point to BK channels as important determinants of synaptic transmission properties, particularly at synapses signaling at high frequencies (Hu et al., 2001; Klyachko et al., 2001; Gu et al., 2007). As BK channels participate in action potential repolarization, thereby altering their shape (Storm, 1987; Vergara et al., 1998), changes in the distance between these channels and their $\mathrm{Ca}^{2+}$ source might modify action potential duration during MOC-OHC synapse maturation. Despite the greater distance between L-type VGCCs and BK channels at hearing onset, our results show that the role of this type of $\mathrm{K}^{+}$ channels would still be crucial for shaping the postsynaptic responses of $\mathrm{OHCs}$ on $\mathrm{MOC}$ fiber intense activity in response to high-level sounds.

\section{References}

Abe T, Kakehata S, Kitani R, Maruya S, Navaratnam D, Santos-Sacchi J, Shinkawa H (2007) Developmental expression of the outer hair cell motor prestin in the mouse. J Membr Biol 215:49-56.

Art JJ, Fettiplace R (1984) Efferent desensitization of auditory nerve fibre responses in the cochlea of the turtle Pseudemys scripta elegans. J Physiol 356:507-523.

Art JJ, Fettiplace R, Fuchs PA (1984) Synaptic hyperpolarization and inhibition of turtle cochlear hair cells. J Physiol 356:525-550.

Ashmore J (2008) Cochlear outer hair cell motility. Physiol Rev 88:173-210.

Atluri PP, Regehr WG (1996) Determinants of the time course of facilitation at the granule cell to Purkinje cell synapse. J Neurosci 16:5661-5671.
Ballestero J, Zorrilla de San Martín J, Goutman J, Elgoyhen AB, Fuchs PA, Katz E (2011) Short-term synaptic plasticity regulates the level of olivocochlear inhibition to auditory hair cells. J Neurosci 31:14763-14774.

Baur D, Bornschein G, Althof D, Watanabe M, Kulik A, Eilers J, Schmidt H (2015) Developmental tightening of cerebellar cortical synaptic influxrelease coupling. J Neurosci 35:1858-1871.

Blanchet C, Eróstegui C, Sugasawa M, Dulon D (1996) Acetylcholineinduced potassium current of guinea pig outer hair cells: its dependence on a calcium influx through nicotinic-like receptors. J Neurosci 16:25742584.

Boero LE, Castagna VC, Di Guilmi MN, Goutman JD, Elgoyhen AB, GómezCasati ME (2018) Enhancement of the medial olivocochlear system prevents hidden hearing loss. J Neurosci 38:7440-7451.

Borst JG, Sakmann B (1996) Calcium influx and transmitter release in a fast CNS synapse. Nature 383:431-434.

Bourinet E, Stotz SC, Spaetgens RL, Dayanithi G, Lemos J, Nargeot J, Zamponi GW (2001) Interaction of SNX482 with domains III and IV inhibits activation gating of alpha(1E) $(\mathrm{Ca}(\mathrm{V}) 2.3)$ calcium channels. Biophys J 81:79-88.

Brown MC (1989) Morphology and response properties of single olivocochlear fibers in the guinea pig. Hear Res 40:93-109.

Brownell W, Bader C, Bertrand D, de Ribaupierre Y (1985) Evoked mechanical responses of isolated cochlear hair cells. Science 227:194-196.

Bulankina AV, Moser T (2012) Neural circuit development in the mammalian cochlea. Physiology (Bethesda) 27:100-112.

Castellano-Muñoz M, Israel SH, Hudspeth AJ (2010) Efferent control of the electrical and mechanical properties of hair cells in the bullfrog's sacculus. PLoS One 5:e13777.

Catterall WA (2011) Voltage-gated calcium channels. Cold Spring Harb Perspect Biol 3:a003947.

Catterall WA, Few AP (2008) Calcium channel regulation and presynaptic plasticity. Neuron 59:882-901.

Chow KY, Wu C, Sui GP, Fry CH (2003) Role of the T-type Ca2+ current on the contractile performance of guinea pig detrusor smooth muscle. Neurourol Urodyn 22:77-82.

Dallos P (1985) Response characteristics of mammalian cochlear hair cells. J Neurosci 5:1591-1608.

Dallos P (2008) Cochlear amplification, outer hair cells and prestin. Curr Opin Neurobiol 18:370-376.

Debanne D, Guérineau NC, Gähwiler BH, Thompson SM (1996) Pairedpulse facilitation and depression at unitary synapses in rat hippocampus: quantal fluctuation affects subsequent release. J Physiol 491:163-176.

Del Castillo J, Katz B (1954a) Quantal components of the end-plate potential. J Physiol 124:560-573.

Del Castillo J, Katz B (1954b) Statistical factors involved in neuromuscular facilitation and depression. J Physiol 124:574-585.

Deng PY, Rotman Z, Blundon JA, Cho Y, Cui J, Cavalli V, Zakharenko SS, Klyachko VA (2013) FMRP regulates neurotransmitter release and synaptic information transmission by modulating action potential duration via BK channels. Neuron 77:696-711.

Dodge FA Jr, Rahamimoff R (1967) Co-operative action a calcium ions in transmitter release at the neuromuscular junction. J Physiol 193:419-432.

Doering CJ, Zamponi GW (2003) Molecular pharmacology of high voltageactivated calcium channels. J Bioenerg Biomembr 35:491-505.

Dulon D, Luo L, Zhang C, Ryan AF (1998) Expression of small-conductance calcium-activated potassium channels (SK) in outer hair cells of the rat cochlea. Eur J Neurosci 10:907-915.

Eggermann E, Bucurenciu I, Goswami SP, Jonas P (2011) Nanodomain coupling between $\mathrm{Ca}(2)(+)$ channels and sensors of exocytosis at fast mammalian synapses. Nat Rev Neurosci 13:7-21.

Elgoyhen AB, Vetter DE, Katz E, Rothlin CV, Heinemann SF, Boulter J (2001) alpha10: a determinant of nicotinic cholinergic receptor function in mammalian vestibular and cochlear mechanosensory hair cells. Proc Natl Acad Sci U S A 98:3501-3506.

Fedchyshyn MJ, Wang LY (2005) Developmental transformation of the release modality at the calyx of Held synapse. J Neurosci 25:4131-4140.

Fioravante D, Regehr WG (2011) Short-term forms of presynaptic plasticity. Curr Opin Neurobiol 21:269-274.

Fuchs PA, Glowatzki E, Moser T (2003) The afferent synapse of cochlear hair cells. Curr Opin Neurobiol 13:452-458. 
Gáborján A, Vizi ES (1999) Characterization of voltage dependent calcium channels on the lateral olivocochlear efferent fibers of the guinea pig. Neurosci Lett 269:49-51.

Galambos R (1956) Suppression of auditory nerve activity by stimulation of efferent fibers to cochlea. J Neurophysiol 19:424-437.

Gifford ML, Guinan JJ Jr (1987) Effects of electrical stimulation of medial olivocochlear neurons on ipsilateral and contralateral cochlear responses. Hear Res 29:179-194.

Glowatzki E, Fuchs P (2000) Cholinergic synaptic inhibition of inner hair cells in the neonatal mammalian cochlea. Science 288:2366-2368.

Gómez-Casati ME, Fuchs PA, Elgoyhen AB, Katz E (2005) Biophysical and pharmacological characterization of nicotinic cholinergic receptors in rat cochlear inner hair cells. J Physiol 566:103-118.

Goutman JD, Fuchs PA, Glowatzki E (2005) Facilitating efferent inhibition of inner hair cells in the cochlea of the neonatal rat. J Physiol 566:49-59.

Green GE, Khan KM, Beisel DW, Drescher MJ, Hatfield JS, Drescher DG (1996) Calcium channel subunits in the mouse cochlea. J Neurochem 67:37-45.

Grunnet M, Kaufmann WA (2004) Coassembly of big conductance Ca2+activated $\mathrm{K}+$ channels and L-type voltage-gated $\mathrm{Ca} 2+$ channels in rat brain. J Biol Chem 279:36445-36453.

Gu N, Vervaeke K, Storm JF (2007) BK potassium channels facilitate highfrequency firing and cause early spike frequency adaptation in rat CA1 hippocampal pyramidal cells. J Physiol 580:859-882.

Guinan JJ (1996) Physiology of olivocochlear efferents. In: The cochlea (Dallos P, PopperAN, Fay RR, eds), pp 435-502. New York: Springer.

Guinan JJ (2011) Physiology of the medial and lateral olivocochlear systems. In: Auditory and vestibular efferents (Ryugo DK, Fay RR, Popper AN, eds), pp 39-81. New York: Springer.

Hang J, Pan W, Chang A, Li S, Li C, Fu M, Tang J (2016) Synchronized progression of prestin expression and auditory brainstem response during postnatal development in rats. Neural Plast 2016:4545826.

He DZ, Dallos P (1999) Development of acetylcholine-induced responses in neonatal gerbil outer hair cells. J Neurophysiol 81:1162-1170.

Hess P, Lansman JB, Tsien RW (1984) Different modes of Ca channel gating behaviour favoured by dihydropyridine $\mathrm{Ca}$ agonists and antagonists. Nature 311:538-544.

Hu H, Shao LR, Chavoshy S, Gu N, Trieb M, Behrens R, Laake P, Pongs O, Knaus HG, Ottersen OP, Storm JF (2001) Presynaptic $\mathrm{Ca}^{2+}$-activated $\mathrm{K}^{+}$ channels in glutamatergic hippocampal terminals and their role in spike repolarization and regulation of transmitter release. J Neurosci 21:95859597.

Hudspeth A (1997) How hearing happens. Neuron 19:947-950.

Inagaki A, Ugawa S, Yamamura H, Murakami S, Shimada S (2008) The CaV3.1 T-type $\mathrm{Ca} 2+$ channel contributes to voltage-dependent calcium currents in rat outer hair cells. Brain Res 1201:68-77.

Iwasaki S, Takahashi T (1998) Developmental changes in calcium channel types mediating synaptic transmission in rat auditory brainstem. J Physiol 509:419-423.

Iwasaki S, Takahashi T (2001) Developmental regulation of transmitter release at the calyx of Held in rat auditory brainstem. J Physiol 534:861871

Iwasaki S, Momiyama A, Uchitel OD, Takahashi T (2000) Developmental changes in calcium channel types mediating central synaptic transmission. J Neurosci 20:59-65.

Jackman SL, Regehr WG (2017) The mechanisms and functions of synaptic facilitation. Neuron 94:447-464.

Katz B, Miledi R (1968) The role of calcium in neuromuscular facilitation. J Physiol 195:481-492.

Katz E, Ferro PA, Weisz G, Uchitel OD (1996) Calcium channels involved in synaptic transmission at the mature and regenerating mouse neuromuscular junction. J Physiol 497:687-697.

Katz E, Protti DA, Ferro PA, Rosato Siri MD, Uchitel OD (1997) Effects of $\mathrm{Ca} 2+$ channel blocker neurotoxins on transmitter release and presynaptic currents at the mouse neuromuscular junction. Br J Pharmacol 121:1531-1540.

Kearney G, de San Martin Z, Vattino J, Elgoyhen AB LG, Wedemeyer C, Katz E (2019) Developmental synaptic changes at the transient olivocochlear-inner hair cell synapse. J Neurosci 39:3360-3375.

Klyachko VA, Ahern GP, Jackson MB (2001) cGMP-mediated facilitation in nerve terminals by enhancement of the spike afterhyperpolarization. Neuron 31:1015-1025.
Knirsch M, Brandt N, Braig C, Kuhn S, Hirt B, Münkner S, Knipper M, Engel J (2007) Persistence of $\mathrm{Ca}_{\mathrm{v}} 1.3 \mathrm{Ca}^{2+}$ channels in mature outer hair cells supports outer hair cell afferent signaling. J Neurosci 27:6442-6451.

Kochubey O, Babai N, Schneggenburger R (2016) A synaptotagmin isoform switch during the development of an identified CNS synapse. Neuron 90:984-999.

Leary S, Underwood W, Anthony R, Cartner S, Corey D, Grandin T, Greenacre C, Gwaltney-Brant S, McCrackin MA, Meyer R, Miller D, Shearer J, Yanong R (2013) AVMA guidelines for the euthanasia of animals. Schaumburg, IL: American Veterinary Medical Association.

Lee JH, Gomora JC, Cribbs LL, Perez-Reyes E (1999) Nickel block of three cloned T-type calcium channels: low concentrations selectively block alpha1H. Biophys J 77:3034-3042.

Lelli A, Asai Y, Forge A, Holt JR, Géléoc GS (2009) Tonotopic gradient in the developmental acquisition of sensory transduction in outer hair cells of the mouse cochlea. J Neurophysiol 101:2961-2973.

Levic S, Dulon D (2012) The temporal characteristics of Ca2+ entry through L-type and T-type Ca2 + channels shape exocytosis efficiency in chick auditory hair cells during development. J Neurophysiol 108:3116-3123.

Liberman MC (1991) The olivocochlear efferent bundle and susceptibility of the inner ear to acoustic injury. J Neurophysiol 65:123-132.

Liberman MC, Brown MC (1986) Physiology and anatomy of single olivocochlear neurons in the cat. Hear Res 24:17-36.

Maison SF, Luebke AE, Liberman MC, Zuo J (2002) Efferent protection from acoustic injury is mediated via $\alpha 9$ nicotinic acetylcholine receptors on outer hair cells. J Neurosci 22:10838-10846.

Mallart A, Martin AR (1967) An analysis of facilitation of transmitter release at the neuromuscular junction of the frog. J Physiol 193:679-694.

Marcotti W, Kros CJ (1999) Developmental expression of the potassium current IK,n contributes to maturation of mouse outer hair cells. J Physiol 520 Pt 3:653-660.

Marrion NV, Tavalin SJ (1998) Selective activation of Ca2+-activated K+ channels by co-localized $\mathrm{Ca} 2+$ channels in hippocampal neurons. Nature 395:900-905.

Michna M, Knirsch M, Hoda JC, Muenkner S, Langer P, Platzer J, Striessnig J, Engel J (2003) Cav1.3 (alpha1D) Ca2 + currents in neonatal outer hair cells of mice. J Physiol 553:747-758.

Mintz IM, Bean BP (1993) Block of calcium channels in rat neurons by synthetic omega-Aga-IVA. Neuropharmacology 32:1161-1169.

Mintz IM, Sabatini BL, Regehr WG (1995) Calcium control of transmitter release at a cerebellar synapse. Neuron 15:675-688.

Momiyama T (2003) Parallel decrease in omega-conotoxin-sensitive transmission and dopamine-induced inhibition at the striatal synapse of developing rats. J Physiol 546:483-490.

Müller M, Goutman JD, Kochubey O, Schneggenburger R (2010) Interaction between facilitation and depression at a large CNS synapse reveals mechanisms of short-term plasticity. J Neurosci 30:2007-2016.

Murthy VN, Sejnowski TJ, Stevens CF (1997) Heterogeneous release properties of visualized individual hippocampal synapses. Neuron 18:599-612.

Myoga MH, Regehr WG (2011) Calcium microdomains near R-type calcium channels control the induction of presynaptic long-term potentiation at parallel fiber to Purkinje cell synapses. J Neurosci 31:5235-5243.

Nakamura Y, Harada H, Kamasawa N, Matsui K, Rothman JS, Shigemoto R, Silver RA, DiGregorio DA, Takahashi T (2015) Nanoscale distribution of presynaptic $\mathrm{Ca}(2+)$ channels and its impact on vesicular release during development. Neuron 85:145-158.

Nanou E, Catterall WA (2018) Calcium channels, synaptic plasticity, and neuropsychiatric disease. Neuron 98:466-481.

Neher E (1998) Vesicle pools and Ca2+ microdomains: new tools for understanding their roles in neurotransmitter release. Neuron 20:389-399.

Newcomb R, Szoke B, Palma A, Wang G, Chen X, Hopkins W, Cong R, Miller J, Urge L, Tarczy-Hornoch K, Loo JA, Dooley DJ, Nadasdi L, Tsien RW, Lemos J, Miljanich G (1998) Selective peptide antagonist of the class E calcium channel from the venom of the tarantula Hysterocrates gigas. Biochemistry 37:15353-15362.

Obejero-Paz CA, Gray IP, Jones SW (2008) Ni2 + block of CaV3.1 (alpha1G) T-type calcium channels. J Gen Physiol 132:239-250.

Oliver D, Fakler B (1999) Expression density and functional characteristics of the outer hair cell motor protein are regulated during postnatal development in rat. J Physiol 519:791-800. 
Oliver D, Klöcker N, Schuck J, Baukrowitz T, Ruppersberg JP, Fakler B (2000) Gating of $\mathrm{Ca} 2+$-activated $\mathrm{K}+$ channels controls fast inhibitory synaptic transmission at auditory outer hair cells. Neuron 26:595-601.

Olivera BM, Miljanich GP, Ramachandran J, Adams ME (1994) Calcium channel diversity and neurotransmitter release: the omega-conotoxins and omega-agatoxins. Annu Rev Biochem 63:823-867.

Plant TD, Schirra C, Katz E, Uchitel OD, Konnerth A (1998) Single-cell RTPCR and functional characterization of $\mathrm{Ca}^{2+}$ channels in motoneurons of the rat facial nucleus. J Neurosci 18:9573-9584.

Pouzat C, Hestrin S (1997) Developmental regulation of basket/stellate cell $\rightarrow$ Purkinje cell synapses in the cerebellum. J Neurosci 17:9104-9112.

Raffaelli G, Saviane C, Mohajerani MH, Pedarzani P, Cherubini E (2004) BK potassium channels control transmitter release at CA3-CA3 synapses in the rat hippocampus. J Physiol 557:147-157.

Rajan R (2000) Centrifugal pathways protect hearing sensitivity at the cochlea in noisy environments that exacerbate the damage induced by loud sound. J Neurosci 20:6684-6693.

Reid CA, Bekkers JM, Clements JD (2003) Presynaptic Ca2+ channels: a functional patchwork. Trends Neurosci 26:683-687.

Ricoy UM, Frerking ME (2014) Distinct roles for Cav2.1-2.3 in activity-dependent synaptic dynamics. J Neurophysiol 111:2404-2413.

Roberts WM, Jacobs RA, Hudspeth AJ (1990) Colocalization of ion channels involved in frequency selectivity and synaptic transmission at presynaptic active zones of hair cells. J Neurosci 10:3664-3684.

Robertson D, Gummer M (1985) Physiological and morphological characterization of efferent neurones in the guinea pig cochlea. Hear Res 20:63-77.

Robitaille R, Adler EM, Charlton MP (1993a) Calcium channels and calcium-gated potassium channels at the frog neuromuscular junction. J Physiol Paris 87:15-24.

Robitaille R, Garcia ML, Kaczorowski GJ, Charlton MP (1993b) Functional colocalization of calcium and calcium-gated potassium channels in control of transmitter release. Neuron 11:645-655.

Rohmann KN, Wersinger E, Braude JP, Pyott SJ, Fuchs PA (2015) Activation of BK and SK channels by efferent synapses on outer hair cells in highfrequency regions of the rodent cochlea. J Neurosci 35:1821-1830.

Rosato Siri MD, Uchitel OD (1999) Calcium channels coupled to neurotransmitter release at neonatal rat neuromuscular junctions. J Physiol 514:533-540.

Rosato-Siri MD, Piriz J, Tropper BA, Uchitel OD (2002) Differential Ca2+dependence of transmitter release mediated by P/Q- and N-type calcium channels at neonatal rat neuromuscular junctions. Eur J Neurosci 15:1874-1880.

Roux I, Wersinger E, McIntosh JM, Fuchs PA, Glowatzki E (2011) Onset of cholinergic efferent synaptic function in sensory hair cells of the rat cochlea. J Neurosci 31:15092-15101.

Schiess AR, Scullin C, Partridge LD (2010) Maturation of Schaffer collateral synapses generates a phenotype of unreliable basal evoked release and very reliable facilitated release. Eur J Neurosci 31:1377-1387.

Sheng J, He L, Zheng H, Xue L, Luo F, Shin W, Sun T, Kuner T, Yue DT, Wu LG (2012) Calcium-channel number critically influences synaptic strength and plasticity at the active zone. Nat Neurosci 15:998-1006.

Simmons DD (2002) Development of the inner ear efferent system across vertebrate species. J Neurobiol 53:228-250.

Storm JF (1987) Action potential repolarization and a fast after-hyperpolarization in rat hippocampal pyramidal cells. J Physiol 385:733-759.

Sugiura Y, Ko CP (1997) Novel modulatory effect of L-type calcium channels at newly formed neuromuscular junctions. J Neurosci 17:1101-1111.

Takahashi T, Forsythe ID, Tsujimoto T, Barnes-Davies M, Onodera K (1996) Presynaptic calcium current modulation by a metabotropic glutamate receptor. Science 274:594-597.

Taranda J, Maison SF, Ballestero JA, Katz E, Savino J, Vetter DE, Boulter J, Liberman MC, Fuchs PA, Elgoyhen AB (2009) A point mutation in the hair cell nicotinic cholinergic receptor prolongs cochlear inhibition and enhances noise protection. PLoS Biol 7:e18.

Taschenberger H, von Gersdorff H (2000) Fine-tuning an auditory synapse for speed and fidelity: developmental changes in presynaptic waveform, EPSC kinetics, and synaptic plasticity. J Neurosci 20:9162-9173.

Taschenberger H, Leão RM, Rowland KC, Spirou GA, von Gersdorff $\mathrm{H}$ (2002) Optimizing synaptic architecture and efficiency for high-frequency transmission. Neuron 36:1127-1143.

Timmermann DB, Westenbroek RE, Schousboe A, Catterall WA (2002) Distribution of high-voltage-activated calcium channels in cultured gamma-aminobutyric acidergic neurons from mouse cerebral cortex. J Neurosci Res 67:48-61.

Tsien RY (1981) A non-disruptive technique for loading calcium buffers and indicators into cells. Nature 290:527-528.

Tymianski M, Spigelman I, Zhang L, Carlen PL, Tator CH, Charlton MP, Wallace MC (1994) Mechanism of action and persistence of neuroprotection by cell-permeant $\mathrm{Ca} 2+$ chelators. J Cereb Blood Flow Metab 14:911-923.

Vergara C, Latorre R, Marrion NV, Adelman JP (1998) Calcium-activated potassium channels. Curr Opin Neurobiol 8:321-329.

Vivas O, Moreno CM, Santana LF, Hille B (2017) Proximal clustering between $\mathrm{BK}$ and $\mathrm{CaV} 1.3$ channels promotes functional coupling and $\mathrm{BK}$ channel activation at low voltage. Elife 6:e28029.

Waguespack J, Salles FT, Kachar B, Ricci AJ (2007) Stepwise morphological and functional maturation of mechanotransduction in rat outer hair cells. J Neurosci 27:13890-13902.

Waka N, Knipper M, Engel J (2003) Localization of the calcium channel subunits Cav1.2 (alpha1C) and Cav2.3 (alpha1E) in the mouse organ of Corti. Histol Histopathol 18:1115-1123.

Wedemeyer C, Vattino LG, Moglie MJ, Ballestero J, Maison SF, Di Guilmi MN, Taranda J, Liberman MC, Fuchs PA, Katz E, Elgoyhen AB (2018) A gain-of-function mutation in the $\alpha 9$ nicotinic acetylcholine receptor alters medial olivocochlear efferent short-term synaptic plasticity. J Neurosci 38:3939-3954.

Weisstaub N, Vetter DE, Elgoyhen AB, Katz E (2002) The alpha9alpha10 nicotinic acetylcholine receptor is permeable to and is modulated by divalent cations. Hear Res 167:122-135.

Wersinger E, McLean WJ, Fuchs PA, Pyott SJ (2010) BK channels mediate cholinergic inhibition of high frequency cochlear hair cells. PLoS One 5: e13836.

Wiederhold ML, Kiang NYS (1970) Effects of electrical stimulation of the crossed olivocochlear bundle on cat single auditory nerve fibers. J Acoust Soc Am 48:950-965.

Womack MD, Chevez C, Khodakhah K (2004) Calcium-activated potassium channels are selectively coupled to P/Q-type calcium channels in cerebellar Purkinje neurons. J Neurosci 24:8818-8822.

Wu LG, Westenbroek RE, Borst JG, Catterall WA, Sakmann B (1999) Calcium channel types with distinct presynaptic localization couple differentially to transmitter release in single calyx-type synapses. J Neurosci 19:726-736.

Yamamoto K, Kobayashi M (2018) Opposite roles in short-term plasticity for $\mathrm{N}$-type and P/Q-type voltage-dependent calcium channels in GABAergic neuronal connections in the rat cerebral cortex. J Neurosci 38:9814-9828.

Zachary S, Nowak N, Vyas P, Bonanni L, Fuchs PA (2018) Voltage-gated calcium influx modifies cholinergic inhibition of inner hair cells in the immature rat cochlea. J Neurosci 38:5677-5687.

Zorrilla de San Martín J, Pyott S, Ballestero J, Katz E (2010) $\mathrm{Ca}^{2+}$ and $\mathrm{Ca}^{2+}$ activated $\mathrm{K}^{+}$channels that support and modulate transmitter release at the olivocochlear efferent-inner hair cell synapse. J Neurosci 30:1215712167.

Zucker RS, Regehr WG (2002) Short-term synaptic plasticity. Annu Rev Physiol 64:355-405. 